\title{
Carbon-Based Materials for the Development of Highly Dispersed Metal Catalysts: Towards Highly Performant Catalysts for Fine Chemical Synthesis
}

\author{
Elena Pérez-Mayoral ${ }^{1, *}$, Ines Matos ${ }^{2, *}$, María Bernardo ${ }^{2}{ }^{\oplus}$, Marcia Ventura ${ }^{2}$ \\ and Isabel M. Fonseca ${ }^{2}$ \\ 1 Departamento de Química Inorgánica y Química Técnica, UNED, Urbanización Monte Rozas, \\ Avda. Esparta s/n Ctra. de Las Rozas al Escorial Km, E-528232 Las Rozas-Madrid, Spain \\ 2 LAQV/REQUIMTE, Departamento de Química, Faculdade de Ciências e Tecnologia, Universidade Nova de \\ Lisboa, 2829-516 Caparica, Portugal; maria.b@fct.unl.pt (M.B.); mm.ventura@fct.unl.pt (M.V.); \\ blo@fct.unl.pt (I.M.F.) \\ * Correspondence: eperez@ccia.uned.es (E.P.-M.); ines.matos@fct.unl.pt (I.M.); \\ Tel.: +34-91-398-9047 (E.P.-M.); +351-212-948-385 (I.M.)
}

Received: 2 November 2020; Accepted: 28 November 2020; Published: 2 December 2020

\begin{abstract}
Single-atom catalysts (SACs), consisting of metals atomically dispersed on a support, are considered as advanced materials bridging homogeneous and heterogeneous catalysis, representing the catalysis at the limit. The enhanced performance of these catalysts is due to the combination of distinct factors such as well-defined active sites, comprising metal single atoms in different coordination environments also varying its valence state and strongly interacting with the support, in this case porous carbons, maximizing then the metal efficiency in comparison with other metal surfaces consisting of metal clusters and/or metal nanoparticles. The purpose of this review is to summarize the most recent advances in terms of both synthetic strategies of producing porous carbon-derived SACs but also its application to green synthesis of highly valuable compounds, an area in which the homogeneous catalysts are classically used. Porous carbon-derived SACs emerge as a type of new and eco-friendly catalysts with great potential. Different types of carbon forms, such as multi-wall carbon nanotubes (MWCNTs), graphene and graphitic carbon nitride or even others porous carbons derived from Metal-Organic-Frameworks (MOFs) are recognized. Although it represents an area of expansion, experimentally and theoretically, much more future efforts are needed to explore them in green fine chemical synthesis.
\end{abstract}

Keywords: porous carbons; atomically dispersed metal catalysts; fine chemicals

\section{Introduction}

Catalysis contributes to enhance our quality of life as a key technology in producing valuable compounds such as plastics, flavors, perfumes, pharmaceuticals, among many other essential chemical products in today's society. In the frame of environmental sustainability, the scientific community is immersed in the development of new, advanced, and more sophisticated materials with great potential, particularly acting as highly performant catalysts for fine chemical synthesis. In this context, the use of metal supported catalysts is widely extended in fine chemical production, especially metal-supported carbon-based materials [1]. In fact, BASF is a leader in providing catalytic technologies useful in the pharmaceutical and fine chemical industry, for instance heterogeneous precious metals catalysts such as $\mathrm{Pd}, \mathrm{Pt}, \mathrm{Rh}, \mathrm{Ru}$, etc., dispersed on carbon and other supports.

Inertness, surface area, porosity, surface chemistry and purity are crucial parameters conditioning the activity and selectivity of heterogeneous catalysts. The high thermal and chemical stability, in acid 
or basic media, of carbon materials together with its low corrosion capability and easily tunable surface chemistry, using chemical or thermal methods or even by post-functionalization, make them almost ideal and versatile catalysts or supports for fine chemical synthesis [2-5].

Other aspects, such as the metal loading, homogeneous distribution, and high dispersion of metal nanoparticles, conditioned by the surface chemistry of the support, notably influence the catalytic performance maximizing the metal efficiency. Therefore, the study of metal-supported, size-limited particles is an issue of capital importance in heterogeneous catalytic processes [6]. Recently, Liu and Corma (2018) summarized the influence of the metal species size on the catalytic performance of different heterogeneously catalyzed reactions [7].

In this context, new advanced highly atomically dispersed metal catalysts, among them the ones known as single-atom catalysts (SACs), emerge as promising catalysts offering high activity and improved selectivity. Metal single atoms can hardly exist by themselves, their presence at the surface being only possible if strong metal-support interactions are stablished. Then, the functions or defects at the support surface plays an important role to prevent the metal cluster aggregation or sintering. In this type of catalysts, the isolated active centers are randomly distributed, generating different heterogenous coordination types, and it is strongly depending on supports nature [8-10]. The development of SACs could begin when the catalytic behavior of gold small clusters supported on different oxides for hydrogen and carbon monoxide oxidation was reported. Haruta et al. (1989) reported that the electronic states of the outer surface gold atoms are modified when interacting with supports, thus contributing to the birth of the catalysis at the limit [11,12]. This type of catalysis could be like enzymatic homogeneous catalysis in which transition metal ions are single active sites. Therefore, it can be said that the use of SACs potentially presents the advantages of both homogeneous and heterogeneous catalysis.

Among the supports reported for the development of SACs are certainly other metals, metal oxides and porous carbon materials [13]. Interestingly, some examples of metal single atoms immobilized on Metal-Organic-Frameworks (MOFs) [14] and zeolites [15,16] are also reported. According to this scenario, the purpose of this review is to summarize the different synthetic strategies to prepare highly metal dispersed porous carbon-based materials as a type of sustainable and environmentally friendly catalysts, including carbon nanotubes, graphene and graphene oxide and $N$-doped carbon material as graphitic carbon nitride applied in catalysis and, more specifically, in fine chemical synthesis [17-19].

\section{Carbon Materials as Ideal Supports for Development of Highly Dispersed Metal Catalyst}

Carbon materials such as biomass and MOF-derived porous carbons, carbon nanotubes, graphene and graphene oxide, and graphitic carbon nitride have been extensively used as catalyst supports due to their well-defined and custom-tailored properties such as surface area, chemical and thermal stability, electronic conductivity, easy heteroatom doping and controllable defect engineering [19-21]. In addition, they can be prepared from low cost precursors such as biowastes, which represents a huge advantage.

\subsection{Synthetic Strategies and Properties}

The synthetic strategies adopted to prepare SACs into carbon materials should guarantee well dispersed active single-atom metals to prevent their further agglomeration and improve the catalytic activity. Defect and doping sites are particularly important to anchor the metal active phases.

\subsubsection{Impregnation—Wet and Dry Methods}

Impregnation is considered as a post-treatment method of the carbon support since the incorporation of the SACs is performed in the carbon material and not during the synthesis of the carbon support. The wet impregnation method consists of introduction of the liquid solution containing the metal precursor into the carbon porous support providing a strong anchoring of the atoms onto the support. In contrast, a dry method usually provides weaker interactions between the 
metal and the support [17]. Wet impregnation of carbon support usually comprises the following steps: incorporation of the active metal into the support through a solid-liquid mixing; drying of the mixture to eliminate the solvent which contains the metallic precursor; and finally a calcination and/or a reduction step (under $\mathrm{H}_{2}$ atmosphere) $[17,18]$. Recent works reporting wet impregnation methods towards SACs over carbon materials have been published: palladium-cobalt phosphide $(\mathrm{Pd}-\mathrm{Co} 2 \mathrm{P})$ nanoparticles with $\mathrm{Pd}$ single atoms anchored on graphene oxide were used in the ethanol electro-oxidation reaction [22]; single atomic Co supported on phosphorized carbon nitride nanosheets was applied in electrocatalytic alkaline hydrogen evolution reaction (HER) [23]; atomically dispersed Pd onto the surface of nitrogen-doped carbon cages prepared from pyrolysis of hollow ZIF-8 was applied in the electrocatalytic reduction of oxygen [24]; Fe-SACs were incorporated in functionalized carbon cloths with $\mathrm{O}$ and $\mathrm{N}$ groups [25]; bifunctional $\mathrm{Ru} / \mathrm{N}$-doped carbon (activated coal and graphene nanoplatelets) was used as a catalyst of cellobiose hydrogenolysis into sorbitol [26]; Ni single atoms in nitrogen doped ultrathin porous carbon templated from porous $\mathrm{g}-\mathrm{C}_{3} \mathrm{~N}_{4}$ was used for the $\mathrm{CO}_{2}$ reduction [27]; atomic $\mathrm{Ru}-\mathrm{N}$ sites on boron-doped mesoporous carbon spheres were impregnated followed by mild photo-activation and used as an electrocatalyst for HER [28].

Dry methods consist basically of the physical mixture of the carbon support with the SACs. Recently, strategies such as ball milling are being presented given its simplicity and fastness, providing high efficiency in atomically dispersing metallic catalysts. Jin et al. (2020), for example, synthesized atomically dispersed $\mathrm{Pt}$ onto $\mathrm{N}$-doped carbon support by using the ball milling method and successfully applied the developed materials as electrocatalyst for the HER [29]. Using another methodology, Indium-C bonds were formed along the broken edges of graphitic nanoplatelets by dry ball-milling graphite in the presence of Indium beads and the resulting material was tested as an electrocatalyst for oxygen reduction reaction (ORR) [30]. It was also reported that the as-cast AB5 alloy powders were ball milled with carbon nanotubes and the resulting composite was employed as anode catalyst for direct borohydride fuel cell [31].

\subsubsection{Organometallic Compounds}

A great number of efficient organometallic compounds have been developed and applied as homogeneous catalysts. However, although the majority of these compounds exhibit high catalytic activity and selectivity, they are usually sensitive to moisture and/or air and are difficult to separate from the products [32]. Also, for reactions in aqueous solutions, it is very difficult to get an organometallic compound that can function as a molecular catalyst with high efficiency and durability over a wide $\mathrm{pH}$ range [33]. Hybrid materials constituted by supported metal complexes can be designed as heterogeneous catalysts able to overcome the main problems associated with the use of the metal complexes alone, with improved catalytic performance. Graphene and graphene oxide have been applied in recent years for the synthesis of graphene-supported metal complexes [34,35]. According to Kharisov et al. (2016), there are several ligands that can establish interactions with graphene, among them are the $N$-containing ligands, such as Schiff bases and porphyrins as well as $\sigma$ - and $\pi$ - ligands, such as carbonyls, cyclopentadienyls and pyrene [34]. Some of these ligands have been used on the synthesis of hybrid catalysts: zirconocene or titanocene complexes have been attached to reduced graphene oxide via $\pi-\pi$ interactions between the cyclopentadienyl rings of the metallocenes and graphitic surface of graphene and applied on the catalysis of polyethylenes with increased molecular weight relative to those produced by free catalysts [36]; in a different approach, cobalt(II), iron(III), or oxovanadium(II) Schiff base metal complexes were covalently grafted on graphene oxide previously functionalized with 3-aminopropyltriethoxysilane and evaluated for the epoxidation of styrene, with higher catalytic performances for the $\mathrm{Co}$ - and Fe- graphene oxide hybrids [37]. As seen, the interaction between the metal complex and the graphene can be covalent or established through a $\pi-\pi$ interaction. The graphene oxide is more often used as support than graphene due to the wider possibilities for reactions of the $\mathrm{O}$-containing functional groups of graphene oxide with the metal complexes. Beyond graphene nanosheets, other carbon nanoforms, such as fullerene [38], carbon nanotubes [39], nanohorns 
and nanodiamonds [40,41], among others [35], can also be used on the synthesis of these hybrids for the application into heterogeneous catalysis. Some recent works apply the resulting hybrids of graphene and metal complexes on the catalysis field. Pour and co-authors (2019) immobilized a new macrocyclic Schiff base copper complex on graphene oxide nanosheets and tested its catalytic activity for olefins epoxidation [42]. The catalyst exhibited high activity and selectivity for cyclohexene (100\% conversion, without by-products) and for norbornene (100\% conversion and $93 \%$ selectivity). The catalyst was reused four consecutive times without significant sacrificing activity. In Ren et al. (2020), a novel terpyridine-based hetero-bimetallic $\mathrm{Ni} / \mathrm{Pd}$ nanosheet supported on graphene oxide was synthesized, exhibiting higher catalytic activity, substrate applicability and recyclability for the Suzuki coupling reaction under mild conditions [43]. On the electrocatalysis field, Sánchez-Page et al. (2020), have determined the influence of graphene sheet properties as supports of iridium-based $N$-heterocyclic carbene hybrid materials on water oxidation [44].

\subsubsection{Deposition}

The deposition methods, chemical vapor deposition (CVD) $[45,46]$ and atomic layer deposition (ALD) $[46,47]$ are in situ preparation techniques and, despite being more complex, are considered more promising for the catalyst performance than other in situ methods such as pyrolysis $[18,46]$ and ball-milling $[29,48]$ or than the post-preparation methods such as impregnation $[17,46]$, which with simpler approaches are usually associated with inhomogeneous particle sizes and compositions. In the case of supported metal catalysts produced through conventional methods, the resulting non-uniformity of metal sites can produce a mixture of reaction products instead of a single desired product and often there is a struggle to find a balance between the activity, selectivity, and stability of the catalyst. The deposition methods, CVD and ALD, allow the control of the catalytic materials synthesis on the atomic level, thus being associated with a more effective control over the size and dispersion of metal sites, as well as to the improvement of the catalytic variables referred above.

\section{Chemical-Vapor-Deposition (CVD)}

The CVD is a vapor-phase deposition process which consists of a substrate exposed to a single or multi-component continuous precursor stream in an inert atmosphere at controlled temperature and pressure. The method has been used extensively to produce catalysts since the 1970s [45] and offers as main advantages (i) the possibility of an efficient and direct deposition of the active metal by reaction with functional groups at the surface of the support and (ii) uniformity on dispersion and narrow size distribution of the metal sites usually observed. Additionally, CVD is also considered a relatively inexpensive process, which allows for a better control over the morphology and thickness of the deposited catalyst layers and that generates more active and selective catalysts when compared to the conventional techniques [45]. This is a method providing stable and active catalysts with a well-defined nanostructure to be used in different areas. As examples for recent applications of this technique in different fields are the synthesis of graphene-derived Cu-SACs for the reaction of oxidative carbonylation of methanol [49], and the synthesis of efficient electrocatalysts based on nanoporous holey graphene doped with both $\mathrm{N}$ and single-atom Mo [50].

\section{Atomic-Layer-Deposition (ALD)}

Despite being largely used, CVD is associated with lower control in the thickness of the catalyst films when compared to ALD method. ALD is a vapor-phase deposition process but contrary to CVD, in the ALD process the substrate is exposed to a sequential/discontinuous stream of precursors and chemical reactants. The ALD process includes mainly four cyclic steps [18], as shown in Figure 1: (i) exposure to the metal precursor; (ii) purge of the ALD reactor; (iii) exposure to a reactive gas to eliminate remaining ligands on the metal; and (iv) a further purge of the ALD reactor. This cycle can be repeated for an established number of times defining the self-limiting nature characteristic of the ALD, which gives to the technique a high degree of precision. The advantages related to this feature include 
uniform surfaces, controlled and accurate film thickness and a high degree of reproducibility [51]. The main disadvantages are the high cost of the operation and its moroseness [18].

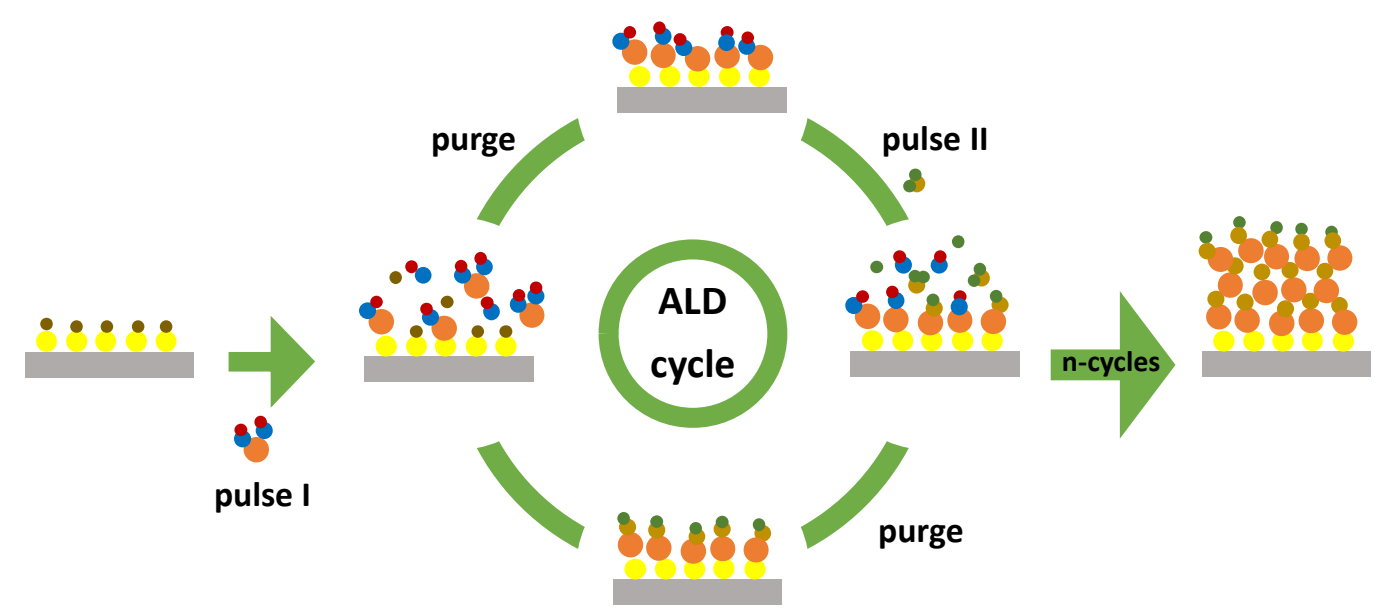

Figure 1. Schematic representation of the atomic layer deposition (ALD) process adapted from $\mathrm{O}^{\prime}$ Neill et al. (2015) [51].

In recent years, ALD has emerged as an interesting tool for the precise design and synthesis of catalytic materials with a controlled size distribution, composition, and active sites. ALD has been used to produce carbon-based SACs using graphene and graphitic carbon nitride as substrates. Sun et al. (2013) developed a practical ALD synthesis of isolated Pt single atoms anchored to graphene nanosheets and $\mathrm{N}$-doped graphene nanosheets [47]. The single $\mathrm{Pt}$ atoms and very small $\mathrm{Pt}$ clusters were grown to form Pt nanoparticles. The number of nanoparticles raised for increasing the ALD cycles. Atomically dispersed $\mathrm{Pd}$ atoms on graphitic carbon nitride $\left(\mathrm{g}-\mathrm{C}_{3} \mathrm{~N}_{4}\right)$ [52] but also on graphene using ALD were also reported [53]. Interestingly, the $\mathrm{Pd}_{1} /$ graphene SAC applied in the hydrogenation of 1,3-butadiene showed about $100 \%$ butenes selectivity and $95 \%$ conversion at mild reaction conditions of about $50{ }^{\circ} \mathrm{C}$. The authors highlighted the excellent durability against deactivation via either aggregation of metal atoms or carbonaceous deposits during a total $100 \mathrm{~h}$ of reaction time. Low Pt content electrocatalysts can also be obtained by the deposition of ultrafine Pt nanoparticles on low-cost carbon-derived substrates using ALD [54]. As an example, Nayak and co-authors deposited Pt on graphene sheets by using ALD to accelerate HER [55]. The activity of the HER was improved by increasing the Pt content, which could be controlled with precision by the number of ALD cycles. In the same field, Zhang et al. (2020) have developed an efficient HER catalyst but using nickel, a non-precious metal. They have reported a novel strategy of fabricating nickel nanograins coated onto a $\mathrm{Co}, \mathrm{N}$-doped carbon framework (Co-NCF@Ni) based on the manipulation of ALD and in situ transformation of a cobalt zeolitic imidazolate framework [56]. The results were considered of great potential in developing both high efficiency transition-metal-based electrocatalysts and flexible $\mathrm{H}_{2}$-production devices for use under extreme conditions. The works described above are examples of the ALD application to the synthesis of carbon-based SACs used on hydrogenation reactions and as electrocatalysts with improved activity, selectivity, and/or stability. The precision and flexibility characteristics of this process allows for the design of catalytic structures to be applicable in a wide range of chemical reactions, among them the conversion of methane, $\mathrm{CO}_{2}$ and biomass, dehydrogenations, etc., [51] but these features can be also relevant for the pharmaceutical and agrochemical industries allowing the synthesis of fine chemicals with an extra degree of purity.

\subsubsection{Pyrolysis}

Pyrolysis is considered an in situ or one-pot synthesis method of SACs supported carbons since the deposition of the active phase occurs simultaneously with the support synthesis. Through this method, high loadings of SACs can be achieved, but the metal loading and its dispersion is more 
difficult to control [18], since at high temperatures metal atoms can be converted to nanoclusters and nanoparticles.

Typical precursors that have been used within this strategy are MOFs that when submitted to high temperatures $\left(>500^{\circ} \mathrm{C}\right)$, under inert atmosphere, are converted into metal/carbon hybrids through the carbonization of the organic coordinating ligand and the deposition/dispersion of the single atoms of metallic species under a strict control of pyrolysis conditions [57]. MOFs are heteroatoms-rich precursors that can be highly dispersed in the resulting carbon materials, providing stable anchoring sites of SACs. Sometimes, it is necessary to perform an acidic leaching of the aggregated metal particles to obtain isolated atoms on the carbon support, which represents a disadvantage. Although some of the high surface area of the original MOFs can be lost during pyrolysis, the resulting carbon still possesses well developed porosity allowing an efficient exposure and accessibility of the generated SACs. Atomically dispersed metal sites in MOF-carbon materials were reviewed by Liang et al. (2018) [57], but recent progressions in the development of these metal/carbon hybrids have been presented: a new $\mathrm{Pt}$ electrocatalyst has been produced by pyrolysis of MOFs with $\mathrm{Pt}^{2+}$ cations and phosphomolybdic acid confined in their pores; the resulting nano-sized molybdenum carbide with a Pt loading of only $0.7 \mathrm{wt} \%$ presented high electrocatalytic activity for HER [58]. In a recent approach, $\mathrm{Ru}$ single atoms distributed in nitrogen-doped porous carbon from ZIF-8 precursor, were synthesized by high-temperature pyrolysis to act as electrocatalysts of $\mathrm{Li}^{-} \mathrm{O}_{2}$ batteries [59]; atomically dispersed Ni-N species in carbon nanotubes have been prepared by pyrolysis of ZnO@ZIF-NiZn core-shell nanorods acting as active electrocatalysts for $\mathrm{CO}_{2}$ reduction reaction [60]; cobalt single atoms supported on $\mathrm{N}$-doped carbon were prepared by the direct pyrolysis of $\mathrm{Zn} / \mathrm{Co}$ bimetallic zeolitic imidazolate framework and used as catalyst in the selective hydrogenation of nitrobenzene [61]; mesoporous carbon nanoframes with hierarchical pore size distribution and atomically dispersed Fe-Nx active sites were synthesized from $\mathrm{Zn}-\mathrm{Fe}$ bimetallic zeolitic imidazole frameworks and applied as electrocatalyst for ORR [62].

Polymer precursors impregnated with a specific metal precursor have been also carbonized to obtain SACs supported on carbon materials. A fluorine-tuned single-atom catalyst with an ultrathin nanosheet morphology and high Ni content of $5.92 \mathrm{wt} \%$ was fabricated by PTFE assisted pyrolysis approach and used for electrocatalytic $\mathrm{CO}_{2}$-to- $\mathrm{CO}$ conversion [63]. Also recently, atomically dispersed Mn single atoms on nitrogen doped carbon were produced from pyrolysis of a polypyrrole polymer produced via in situ polymerization with $\mathrm{MnO}_{2}$ that served as a polymerization initiator of the pyrrole monomers, but also as a sacrificial template and metal source. The obtained materials were employed as photocatalyst in $\mathrm{CO}_{2}$ reduction to produce synthesis gas [64].

Also, Fe rich biomass has recently been used to generate single-atomic $\mathrm{Fe}_{\mathrm{N}} \mathrm{N}_{4}$-contained carbon materials with high-performance for ORR using silica spheres as hard template [65]. Using a different methodology and biomass as the carbon support precursor, Wang et al. (2019) produced oxygen and nitrogen coordinated single copper atom active sites anchored within porous carbon synthesized by direct pyrolysis of $\mathrm{Cu}^{2+}$ saturated aubergine biomass; the authors obtained polymer/aubergine- $\mathrm{Cu}^{2+}$ by immersing $\mathrm{Cu}^{2+}$ saturated aubergine in an aqueous solution of poly(vinyl alcohol) and $\mathrm{KHCO}_{3}$; this mixture was then submitted to pyrolysis treatment at $800{ }^{\circ} \mathrm{C}$ under $\mathrm{N}_{2}$; the resultant electrodes proved to possess exposed rich defects and heteroatoms $(\mathrm{O}, \mathrm{N})$ doped carbon active sites, delivering bifunctional ORR and oxygen evolution reaction (OER) activities [66].

\section{Carbon-Supported Metal Single Atom Catalysts. Application in Fine Chemical Synthesis}

The use of carbon-based SACs with application in fine chemical synthesis is getting much attention mainly because it offers the maximum metal efficiency, while providing high activities and selectivities [18]. In this context, graphene [48,67] and carbon nanotubes (CNT) [68] are often the preferred carbon forms for SACs synthesis because they present relatively large surface area and can be synthesized in high yields, by catalytic CVD. Also relevant is the recently great expansion of carbon nitride and carbon-based materials synthetized with assistance of MOFs. New families of 
porous carbon-based SACs are then summarized in the next sections, classified as different structural carbon forms, involved in the synthesis of valuable compounds mainly through oxidation and hydrogenation reactions, with both types of processes being of utmost importance for chemical industry. These transformations take place in the production of several important compounds such as active pharmaceutical molecules, dyes, rubber chemicals and other chemical upgrade reactions.

\subsection{Carbon Nanotubes}

SAC-based CNTs have been reported catalyzing oxidation of silanes or thiophenol, Suzuki coupling reactions and hydroalkylation reactions. In this regard, considering the great interest in the catalytic properties of gold in the past years, related to particle size, morphology, among others, John et al. (2011) reported a sophisticated synthetic approach to prepare CNT-gold nanohybrids able to efficiently catalyze the oxidation of silanes to silanols as intermediate compounds useful in a great variety of chemical processes (Scheme 1) [69]. Catalysts were synthetized through a layer-by-layer approach roughly consisting of the following steps: (i) multi-walled carbon nanotubes (MWCNTs) covering with diacetylene nitrilotriacetic amphiphile (DANTA), (ii) stabilization by photo-polymerization, (iii) deposition of the second layer by addition of poly(diallyldimethylammonium chloride) (PDADMAC) and, finally, (iv) the resulting twice-coated CNTs treated with freshly gold nanoparticles solution interacting with the PDADMAC network (Figure 2). The authors demonstrated that AuCNT is a totally reusable and selective catalyst affording the corresponding silanols in excellent yield, under mild reaction conditions, even when starting from deactivated or sterically hindered silanes. Even when using lower catalyst amounts $(0.01 \% \mathrm{~mol}), 90 \%$ of phenyldimethylsilanol was obtained in comparison with almost unreactive colloidal Au-nanoparticles or $\mathrm{HAuCl}_{4}$.

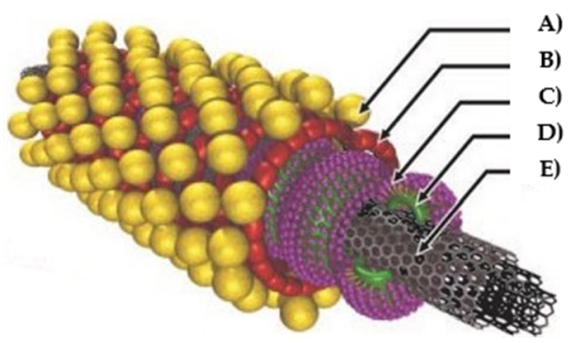

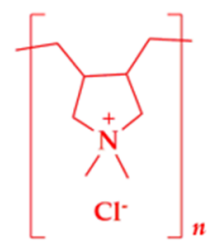

PDADMAC

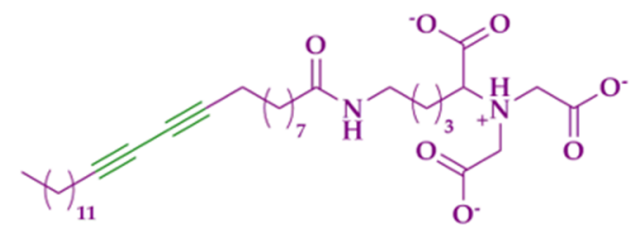

DANTA

Figure 2. Au carbon nanotube (CNT) nanohybrid (A) AuNP; (B) poly(diallyldimethylammonium chloride) (PDADMAC) layer; (C) diacetylene nitrilotriacetic amphiphile (DANTA) nanorings; (D) polymerized region (green); (E) multiwalled CNT. Adapted from [69].

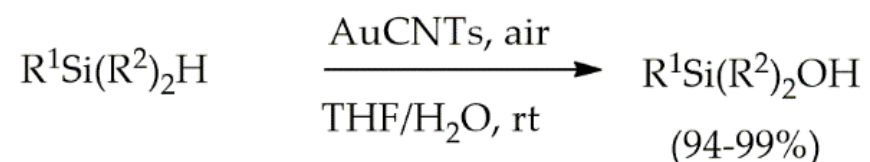

Scheme 1. Oxidation of silanes catalyzed by AuCNT nanohybrid [69].

Regarding another easier and practical approach, Corma et al. (2013) reported a SAC composed by isolated gold atoms supported on functionalized MWCNT active in the aerobic thiophenol oxidation to disulfide, showing similar catalytic activity to sulfhydryl oxidase enzymes [70]. This catalyst is particularly interesting since the authors demonstrated that the single gold atoms were inactive but when aggregated into gold small clusters (5-10 atoms), during the reaction, are able to simultaneously activate thiophenol and $\mathrm{O}_{2}$, as theoretically confirmed, notably increasing its catalytic activity. In this case, the cluster size is a relevant parameter because the catalyst was also inactive when larger nanoparticles were formed.

Other synthetic methodologies for both the confinement of metal species inside the tubular structure or its dispersion over the external surface of CNTs have been reported. The first strategy allows the stabilization and, therefore, the protection of metal atoms or under-coordinated metal sites 
as small clusters. This is the case of Pt@CNT catalyst, consisting of Pt nanoclusters (down to $1 \mathrm{~nm}$ ) within CNT channels (1-1.5 nm in diameter) highly active in the oxidation of toluene [71]. On the other side, Lee et al. (2017) recently reported thiolated MWCNTs, synthetized by using the amidation method from oxidized MWCNTs, able to stabilize Pd or Pt species, denoted as Pt-S-MWNT and Pd-S-MWNT, in which the existence of the single atoms was confirmed [72]. Pt-S-MWNT resulted in highly efficient catalyst for the Suzuki coupling reaction from 4-iodoanisole and 4-methylbenzene boronic acid leading to the corresponding biphenyl derivative in almost quantitative yield, also demonstrating high recyclability (Scheme 2). Its catalytic activity was in a range of 2-30 times higher compared to other traditional catalysts such as $\mathrm{Pt} / \mathrm{C}$. The authors attributed this enhanced activity to the combination of different factors including large surface area, and extraordinarily high Pt particles dispersion evidenced as almost zero-valent $\mathrm{Pt}$ single atoms, in which a fast charge compensation of $\mathrm{Pt}$ by sulfur atoms in organic functions is produced. A similar synthetic strategy has been applied to the preparation of analogous Pt SAC active in intramolecular hydroalkoxylation reaction of unsaturated alcohols in the presence of $\mathrm{PPh}_{3}$ (Scheme 3) [73]. The authors confirmed that the functionalization of the surface with thiol groups was determinant to obtain atomically dispersed Pt-S-MWNT catalyst, observing the formation of metal agglomerates in the absence of those groups. Cyclization of two unsaturated alcohols was investigated, 3-buten-1-ol or 4-penten-1-ol, yielding tetrahydro-2-methylfuran (70\%) or 2-methyloxetane, the last one with only $10 \%$ due to the increased ring strain.

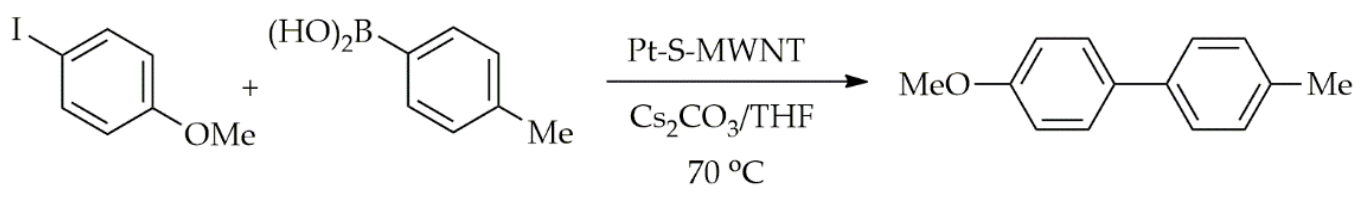

Scheme 2. Suzuki coupling reaction between 4-iodoanisole and 4-methylbenzene boronic acid catalyzed by Pt-S-MWNT [72].

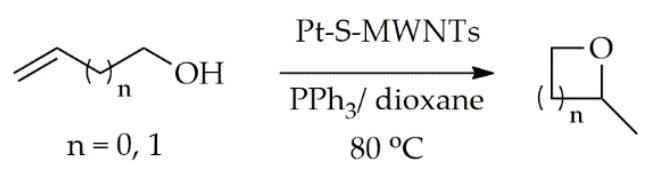

Scheme 3. Cyclization of unsaturated $\gamma$ - or $\delta$-unsaturated alcohols catalyzed by Pt-S-MWNTs [73].

\subsection{Graphene and Graphene Oxide}

Graphene-based materials are excellent and promising candidates for development of SACs due to their unique structural and electric properties. Additionally, the edge sites or carbon vacancies in graphene are key for anchoring metal atoms. In this context, the understanding of the transition metal atoms coordination as single atoms on graphene surface has recently been reviewed [74]. Considering this scenario, and aimed to the application of graphene-based SACs in fine chemical synthesis, an easy and efficient methodology to obtain highly dispersed single $\mathrm{FeN}_{4}$ centers confined in a graphene matrix, $\mathrm{FeN}_{4} / \mathrm{GN}$, has been reported [75]. The synthetic approach consisted of high-energy ball milling of iron phthalocyanine and graphene nanosheets under controllable conditions. This catalyst showed high activity and selectivity in the direct catalytic oxidation of benzene to phenol, in the presence of hydrogen peroxide as benign oxidizing agent, at room temperature or even at $0{ }^{\circ} \mathrm{C}$, in contrast to the high temperatures used in traditional procedures for the $\mathrm{C}-\mathrm{H}$ bond activations $\left(50-140^{\circ} \mathrm{C}\right)$. Concerning benzene oxidation, the iron in $\mathrm{FeN}_{4} / \mathrm{GN}$ catalyst as an unsaturated coordinatively site is able to activate hydrogen peroxide increasing the coordination number to form $\mathrm{Fe}=\mathrm{O}$ functions, as theoretically and experimentally demonstrated (Scheme 4). 


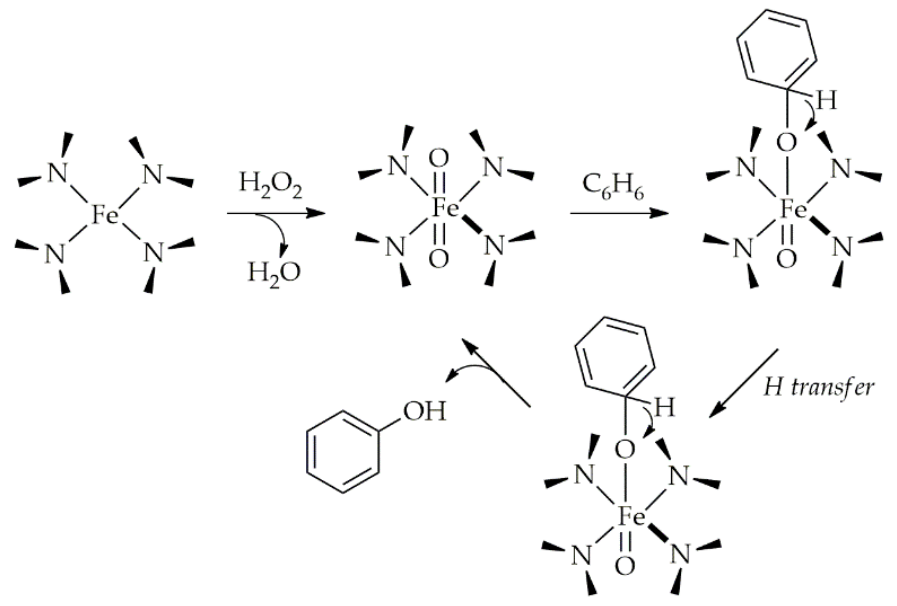

Scheme 4. Direct catalytic oxidation of benzene to phenol, in the presence of hydrogen peroxide, catalyzed by $\mathrm{FeN}_{4} / \mathrm{GN}$ [75].

In another approach, Bakandritsos et al. (2019) recently reported a mixed-valence ionic copper catalyst, prepared from cyanographene, G-CN, in which $3.4 \mathrm{wt} \% \mathrm{Cu}$ ions are homogeneously distributed at the sheet surface as mixed $\mathrm{Cu}(\mathrm{II})$ and $\mathrm{Cu}(\mathrm{I})$ [76]. The presence of $\mathrm{Cu}(\mathrm{I})$ is probably due to specific $\mathrm{Cu}$ interactions developed with G-CN support. This catalyst was used with very low metal loading in the synthesis of imines, by oxidative dehydrogenation of amines to imines, but also ketones from benzylic hydrocarbons, obtaining excellent conversions and selectivities, both as a class of intermediated compounds useful for the production of pharmaceuticals (Schemes 5 and 6). The authors suggested that the imine obtention in the presence of $\mathrm{Cu}(\mathrm{I}) / \mathrm{Cu}(\mathrm{II}) \mathrm{G}-\mathrm{CN}$ catalyst takes place through a reaction mechanism in which $\mathrm{Cu}(\mathrm{I})$ centers is responsible for the $\mathrm{O}_{2}$ activation originating a copper-oxyl intermediate releasing one water molecule. The cyclic intermediate specie involving the two $\mathrm{Cu}$ (II) ions evolved to the imine species, by two-hydrogen abstraction from the neighboring amine, able to react with other benzyl amine molecule affording the corresponding imine with release of water and ammonium (Scheme 7).

$$
\begin{aligned}
& \mathrm{R}^{1} \widehat{\mathrm{NH}_{2}}+\mathrm{R}^{2} \widehat{\mathrm{NH}}_{2} \underset{\mathrm{air}, 85^{\circ} \mathrm{C}}{\stackrel{\mathrm{G}(\mathrm{CN})-\mathrm{Cu}}{\longrightarrow}} \mathrm{R}^{1} \widehat{\mathrm{N}}^{\frown} \mathrm{R}^{2} \\
& \mathrm{R}^{1}=\mathrm{R}^{2}=\mathrm{CH}_{3}-\left(\mathrm{CH}_{2}\right)_{6}, \mathrm{Ph}, p-\mathrm{MeO}-\mathrm{C}_{6} \mathrm{H}_{4}, p-\mathrm{F}-\mathrm{C}_{6} \mathrm{H}_{4},-\mathrm{O}-\mathrm{CH}_{2} \text {, }
\end{aligned}
$$

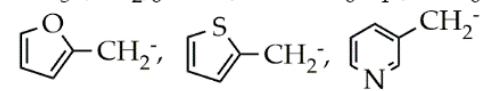

$$
\begin{aligned}
& \mathrm{R}^{1}=\mathrm{Ph} ; \mathrm{R}^{2}=p-\mathrm{MeO}-\mathrm{C}_{6} \mathrm{H}_{4^{\prime}} p-\mathrm{F}-\mathrm{C}_{6}, p-\mathrm{F}_{-} \mathrm{C}_{6} \mathrm{H}_{4^{\prime}} \\
& p \text {-F- } \mathrm{C}_{6} \mathrm{H}_{4}, p-\mathrm{Me}-\mathrm{C}_{6} \mathrm{H}_{4}, p-\mathrm{F}-\mathrm{C}_{6}
\end{aligned}
$$

Scheme 5. Oxidative dehydrogenation of amines to imines catalyzed by $\mathrm{Cu}(\mathrm{I}) / \mathrm{Cu}(\mathrm{II}) \mathrm{G}-\mathrm{CN}$ [76].

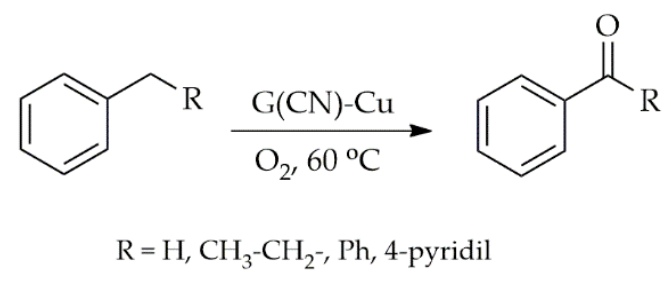

Scheme 6. Oxidation of benzylic hydrocarbons to ketones catalyzed by $\mathrm{Cu}(\mathrm{I}) / \mathrm{Cu}(\mathrm{II}) \mathrm{G}-\mathrm{CN}$ [76]. 


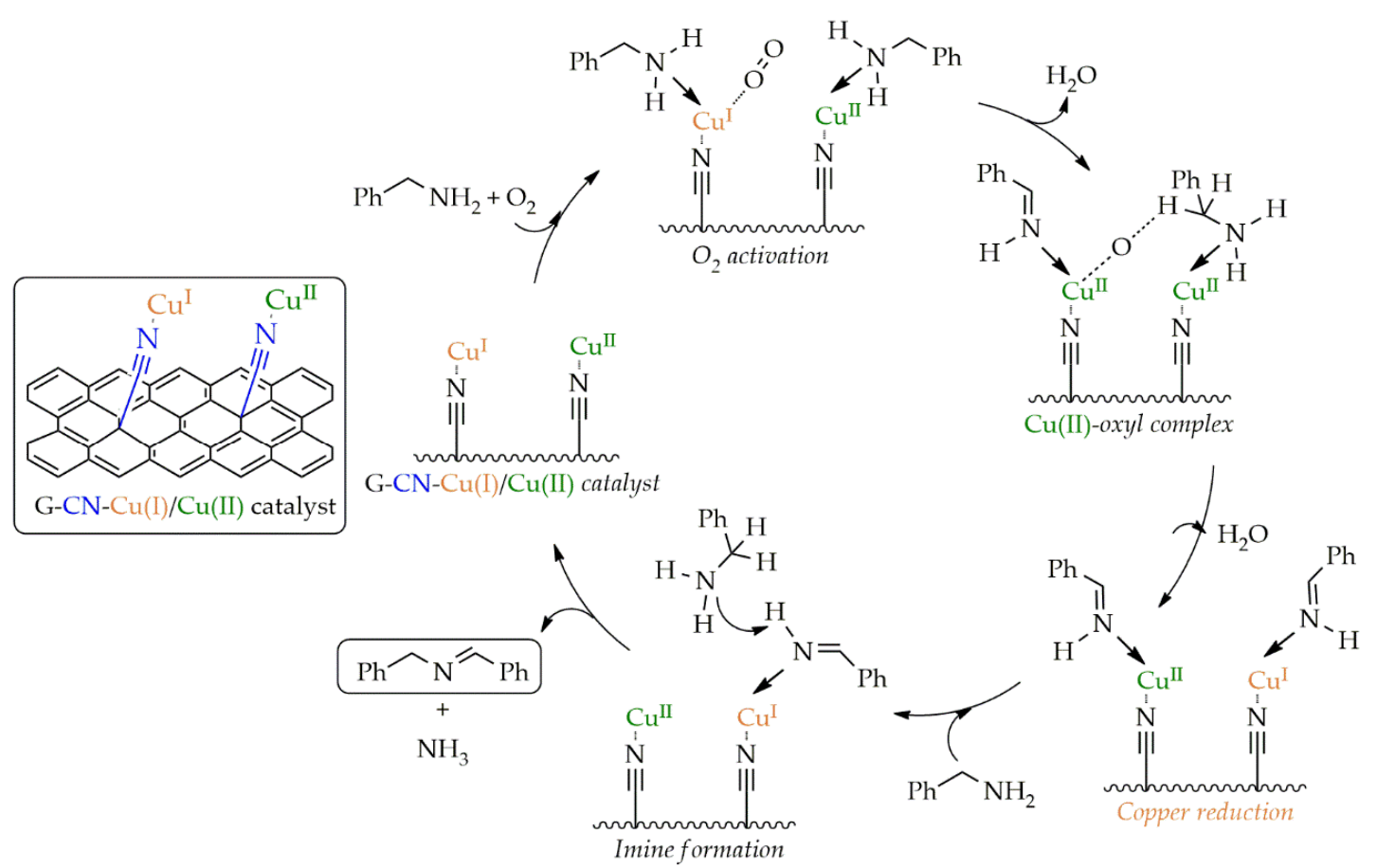

Scheme 7. Catalytic cycle in the oxidative dehydrogenation of benzyl amine catalyzed by $\mathrm{Cu}(\mathrm{I}) / \mathrm{Cu}(\mathrm{II})$ G-CN catalyst [76].

Interestingly, Sun et al. (2018) investigated the catalytic behavior of atomically dispersed Pt atoms on the nitrogen and boron-doped graphene catalysts involved in the direct dehydrogenation of propane [77]. The presence of nitrogen or boron as doper on graphene modifies the Pt electronic structure, since both show an opposite effect on the Pt charge, affecting the catalytic performance. The authors concluded that the pyridine nitrogen doped graphene supporting single $\mathrm{Pt}$ atoms is found to be the most active catalyst, the rational doping being a practical strategy for the optimized development of SACs.

SACs comprising highly dispersed Co atoms onto $N$-modified graphene were also reported for the selective aerobic oxidation of benzylic alcohols to benzaldehydes exhibiting high conversions and selectivities ( $94.8 \%$ of conversion with $97.5 \%$ of selectivity to benzaldehyde) [78]. In this case, the catalysts were prepared from graphene oxide $(\mathrm{GO})$ and $\mathrm{Co}\left(\mathrm{NO}_{3}\right)_{2}$ aqueous solution and subsequent thermal treatment at different temperatures under $\mathrm{NH}_{3}$ ambient. While the oxygen content of the samples diminished when increasing the pyrolysis temperature, the nitrogen loading was increased, favoring thus the coordination with Co and enhancing the catalytic performance.

Considering that Au nanoparticles either alone or supported on inert materials are efficient and selective catalysts for styrene oxidation, the epoxidation of ethylene was theoretically investigated in the presence of $\mathrm{O}_{2}$ using Au atomically dispersed onto graphene. Herein, the defects on graphene played an important role in metal dispersion acting as strong trapping sites and making Au atoms active [79]. The authors suggested that the ethylene oxidation would involve the co-adsorption of both oxygen and ethylene with formation of a peroxametallacycle intermediate which undergoes a dissociation process to give ethylene oxide and one adsorbed $\mathrm{O}$ atom available to start another catalytic cycle. Theoretical calculations indicated that the epoxidation reaction is favored vs. aldehyde formation confirming the great potential of this SAC.

SACs consisting of transition metal supported on graphene catalyzing hydrogenation reactions of nitroarenes or olefins have been also reported as experimental but also theoretical studies. In this context, Wang et al. (2020) very recently reported on a theoretical study, by DFT calculations, concerning the nitrobenzene adsorption on SACs consisting of transition metal single atoms $(\mathrm{Ni}, \mathrm{Cu}, \mathrm{Pd}$, or $\mathrm{Pt}$ ) embedded graphene [80]. Interestingly, this study could contribute to the rational design of stable 
and efficient SACs as electrocatalysts for aniline production under ambient conditions. In this case, the authors demonstrated that $\mathrm{PtN}_{3} / \mathrm{G}$ was found to be the most active catalyst, identifying that the formation of Ph-NOOH intermediate species, strongly binding to $\mathrm{PtN}_{3} / \mathrm{G}$, in the nitrobenzene hydrogenation, could be the potential rate-limiting step and responsible of its superior catalytic activity. Interestingly, Lou et al. (2019) produced a hollow nanocarbon (h-NC) with high density of defective sites, high surface area and developed mesoporosity, in which $\mathrm{Pt}$ atoms are strongly interacting with carbon in graphene sheets, $\mathrm{Pt}_{1} / \mathrm{h}-\mathrm{NC}$ [81]. This mesoporous nanocarbon, prepared by catalytic EtOH reforming/decomposition on $\mathrm{ZnO}$ nanowires surfaces, resulted in excellent and superior catalytic activity in the 3-nitrostyrene hydrogenation to 3-vinylaniline, notably higher than other reported catalysts.

More complex SACs as ordered mesoporous carbons with embedded and well-dispersed transition metal nanoparticles $(\mathrm{Ni}, \mathrm{Co}, \mathrm{Fe})$ modified with nitrogen-doped graphene, showing excellent catalytic performance in the hydrogenation reactions of nitroarenes to anilines in water, have been recently reported [82]. The catalysts presented 2D hexagonally arranged pore structure with a pore size distribution ranging $3.8-4.3 \mathrm{~nm}$, depending of pyrolysis temperature, and exhibiting a well-developed micro- and mesoporosity and high surface area $\left(500 \mathrm{~m}^{2} / \mathrm{g}\right)$. The Ni sample pyrolyzed at $800{ }^{\circ} \mathrm{C}, \mathrm{Ni} / \mathrm{NGr} @ \mathrm{OMC}-800$, resulted in the best catalytic performance yielding aniline in $86 \%$ with $95.6 \%$ of selectivity. The conversion was notably higher than the one obtained for Ni/OMC- 800 without nitrogen-doped activated graphene. Therefore, the presence of Ni/NGr is determinant for a better catalytic performance, attributed to the synergistic effects between Ni nanoparticles and nitrogen-doped graphene.

Analogously, Xi et al. (2018) theoretically investigated, through DFT calculations, the interactions of Pd single atoms on different carbon supports, amorphous carbon, graphene and constructed graphene/amorphous carbon structure [83]. These results indicated that $\mathrm{Pd}$, in this case, is strongly bound on the interface between graphene and amorphous carbon, these interactions being notably superior to those observed for each separately carbon supports, graphene or amorphous carbon. Based on the predictive study, the authors synthesized a Pd SAC consisting of atomically dispersed Pd on graphene/amorphous carbon structure, highly active in the reduction of 4-nitrophenol in the presence of $\mathrm{NaBH}_{4}$ as reducer, but also for Suzuki coupling reaction. The carbon structure of the catalyst consisted of a double-shelled hollow carbon nanosphere comprising reduced graphene oxide (RGO) as the inner shell and amorphous carbon as the outer shell, in which Pd species were incorporated by using the impregnation method. The large specific surface area $\left(667 \mathrm{~m}^{2} / \mathrm{g}\right)$, high accessibility of the active sites as $\mathrm{Pd}$ atoms, in combination to the confinement effect and the strong $\pi-\pi$ stacking interactions between RGO shell and aromatic ring in 4-nitrophenol are probably account for its superior catalytic activity.

Highly stable single-atom $\mathrm{Pd}_{1} /$ graphene catalyst highly active in the selective 1,3-butadiene hydrogenation to butenes, under mild reaction conditions, has been also reported [53,84]. The catalyst was prepared by atomic layer deposition of Pd over reduced graphene oxide, by using palladium hexafluoroacetylacetate $\mathrm{Pd}(\mathrm{hfac})_{2}$. The presence of appropriate type and concentration of surface oxygen functional groups was key to create single atoms on graphene nanosheets. In this case, the thermal deoxygenation of graphene oxide predominantly generated phenolic oxygen species able to interact with $\mathrm{Pd}$ atoms through three $\mathrm{Pd}-\mathrm{C}$ and one Pd-O-C coordinations. The developed catalyst showed an excellent durability, exhibiting total selectivity for the hydrogenation of 1,3-butadiene to butenes, under mild reaction conditions. The notably superior selectivity of this catalyst was attributed to the changes on the adsorption mode of 1,3-butadiene, which is different when extended to $\mathrm{Pd}$ surfaces contained on commercial Pd catalysts or Pd nanoparticles over graphene. The authors proposed the heterolytic dissociation of $\mathrm{H}_{2}$ at the 1,3-butadiene covered single $\mathrm{Pd}$ atom and then the hydrogenation of the $\mathrm{C}=\mathrm{C}$ bond through pseudo Horiuti-Polanyi mechanism. 


\subsection{Carbon Nitride}

Carbon nitride $\left(\mathrm{C}_{3} \mathrm{~N}_{4}\right)$ is a material structurally similar to graphite but covalent $\mathrm{C}-\mathrm{N}$ bonds are present in each layer. These are very thermal and chemically stable structures with very interesting electronic properties.

Due to the abundant coordination sites present in the structure formed by the nitrogen rich heterocycles, these materials are particularly suitable for single atoms stabilization. Additionally, in the edges and defaults of the graphitic sheets of $g-\mathrm{C}_{3} \mathrm{~N}_{4}$ there is the presence of amino groups. These coordination sites and the properties of carbon nitride material can be tailored aiming to specific properties of SACs [85]. A most attractive characteristic of these materials is the possibility of preparing them by using low cost precursors such as urea, thiourea, cyanuric acid, cyanamide and melanine. Biomass waste precursors like chitosan resulted in a sustainable environmentally friendly approach for carbon nitride production [86].

More advanced and tailored structures can be obtained using appropriate synthetic strategies [87]. Mesoporous g- $\mathrm{C}_{3} \mathrm{~N}_{4}$ can be obtained using silica materials as templates through nanocasting methods [88]. Nanosheets and thin films synthesis have been described using similar approaches to graphene manipulation such as sonication-assisted liquid-exfoliation, taking advantages of the similitudes between materials [89]. Nanotubes, nanowires and nanorods of carbon nitride have also been reported [87].

These materials have proven versatility and found applications in several areas, mostly in photocatalysis [90], electrocatalysis [91], sensing [92] and related subjects. Particularly interesting is their application as SACs for different catalytic reactions for fine chemicals, although much less explored.

Searching for a replacement of the Hg-based catalyst normally used in the acetylene hydrochlorination reaction (Scheme 8), of vital importance for the production of PVC, Dai et al. (2015) studied the application of mesoporous carbon nitride as a support for an Au catalyst. The work concluded the effectiveness of the catalysts and the ability of the support to control the metal surface distribution [93].

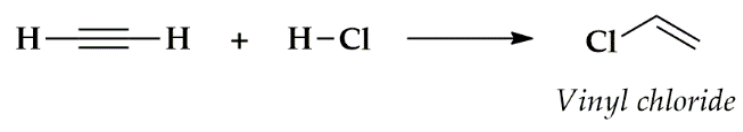

Scheme 8. Acetylene hydrochlorination reaction for PVC production.

Some recent examples of using carbon nitride-based SACs for hydrogenation reactions can be found in the literature. The group of Pérez-Ramírez dedicated some attention to the carbon nitride $\left(C_{3} N_{4}\right)$ Pd SACs for hydrogenation reactions [94]. The authors evaluated $\mathrm{Pd}-\mathrm{C}_{3} \mathrm{~N}_{4}$ catalysts in the semi-hydrogenation of 2-methyl-3-butyn-2-ol, an important building block in the synthesis of vitamin E. Using advanced characterization techniques, the materials were thoroughly studied and DFT calculations were employed to better understand the stabilization of palladium in the distinct carbon nitride scaffolds used. It was possible to establish an inverse correlation between the activity and the degree of oxidation of palladium. In a complementary work, the authors evaluated the influence of heteroatom doping of the surface material on the catalytic performance, and they also assessed the scalability of this catalyst looking at large scale applications [95]. With an optimum $0.25 \mathrm{wt} \%$ phosphorous doping, there was an improvement of catalytic performance presenting a rate over 5 times higher than the pristine $\mathrm{C}_{3} \mathrm{~N}_{4}$. Phosphorus doping increased the electron density of carbon nitride thus lowering the oxidation state of the Pd. In another work, the authors looked to the same reaction and compared the palladium SAC based on exfoliated carbon nitride with other three nitrogen doped carbons, carbon nanofibers, reduced graphene oxide derived from graphene oxide, and mesoporous carbon [96]. The developed work intended to understand the effect of the specific properties of the host material on the catalyst performance and on the metal coordination. The reaction of semi-hydrogenation of 2-methyl-3-butyn-2-ol allowed to distinguish the reactivity of single atoms 
and nanoparticles, and the results showed that it was possible to reach similarly high stability and tunability of the metal in other nitrogen-doped carbon, as is for carbon nitride SACs despite their lower nitrogen contents and greater heterogeneity.

Huang et al. (2017), using ALD, prepared a carbon nitride $\left(\mathrm{g}-\mathrm{C}_{3} \mathrm{~N}_{4}\right)$ presenting atomically dispersed Pd atoms and studied the selective hydrogenation of acetylene [52]. Carbon nitride supported $\mathrm{Pd}$ catalysts revealed higher ethylene selectivities at high acetylene conversions when compared with other supports studied, $\mathrm{Al}_{2} \mathrm{O}_{3}$, and $\mathrm{SiO}_{2}$. Additionally, single-atom $\mathrm{Pd} / \mathrm{C}_{3} \mathrm{~N}_{4}$ catalyst presented improved catalytic performances, compared to nano particle g- $\mathrm{C}_{3} \mathrm{~N}_{4}$-supported Pd catalyst, and demonstrated higher resistance to coke formation.

Hydrogenation and hydrodeoxygenation reactions are extremely relevant in the upgrade of biomass-derived chemicals into value-added products. SACs may play an important role in this area, including carbon nitride supported ones. Palladium catalyst supported on mesoporous graphitic carbon nitride was used in the selective hydrogenation of biomass-derived 5-hydroxymethylfurfural (HMF) to 2,5-dihydroxymethyl-tetrahydrofuran (DHMTHF) [97]. The authors reported a complete conversion of HMF with $96 \%$ selectivity. Tian et al. (2018) reported the temperature-controlled selectivity of hydrogenation and hydrodeoxygenation in the conversion of vanillin in aqueous media by the $\mathrm{Ru}_{1} / \mathrm{mpg}-\mathrm{C}_{3} \mathrm{~N}_{4}$ catalyst [98]. The Ru supported on mesoporous graphitic carbon nitride $\left(\mathrm{Ru} / \mathrm{mpg}-\mathrm{C}_{3} \mathrm{~N}_{4}\right)$ was prepared by a wet impregnation method and revealed excellent catalytic performance for both the hydrogenation and hydrodeoxygenation of vanillin depending on the reaction temperature. The authors reported that the temperature effect was due to a switching between the deoxygenation prohibited and deoxygenation allowed products.

SAC iridium catalysts were prepared with mpg- $\mathrm{C}_{3} \mathrm{~N}_{4}$ and with $\mathrm{TiO}_{2}$ as hosts and investigated for the selective hydrogenation of furfural [99]. This work demonstrated the importance of metal support interactions in the resulting properties of the catalysts. While $\mathrm{Ir} / \mathrm{TiO}_{2}$ showed very high activity, the $\mathrm{Ir} /$ mpg- $\mathrm{C}_{3} \mathrm{~N}_{4}$ sample only resulted in trace product formation.

A palladium catalyst was prepared by microwave-irradiation-assisted deposition on exfoliated graphitic carbon nitride and applied in Suzuki coupling reactions [100]. The catalytic performance of the obtained catalyst was evaluated in the reaction of bromobenzene with phenylboronic acid pinacol ester under optimized conditions (Scheme 9). The catalyst revealed very good catalytic behavior and outperformed other homogeneous catalysts tested as well as more conventional heterogeneous catalyst. Additionally, the catalyst proved to be stable and no leaching was observed. The authors concluded that the carbon nitride support plays a central role in the catalyst properties.
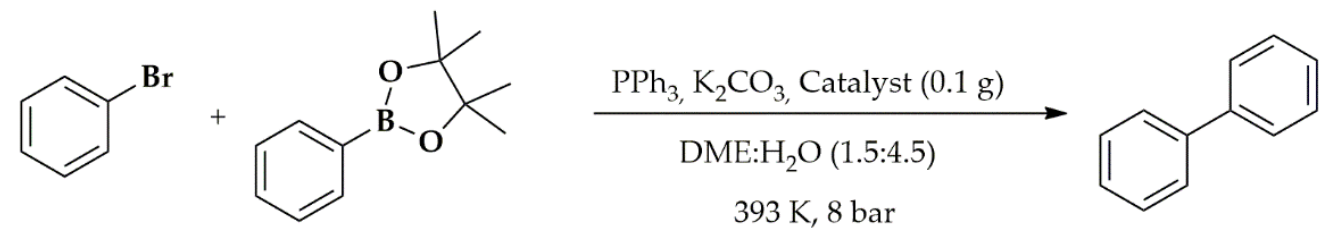

Scheme 9. Suzuki coupling of bromobenzene with phenylboronic acid pinacol ester [100].

\subsection{Carbons from Emerging Precursors: Metal Organic-Frameworks}

MOFs are porous materials composed by the self-assembly of metal ions and organic ligands, also known as crystalline porous coordination polymers. MOFs present high surface areas, high pore volumes, ordered porous structure, abundant metal sites and can be synthesized in a great variety of molecular composition. MOF-derived carbons have received growing attention in the production of a variety of carbon-based nano materials. Several synthetic strategies have been reported for the preparation of MOF-derived carbons and SACs, being pyrolysis always a crucial step [101,102].

Different MOF-derived carbon SACs have been reported in hydrogenation reactions. Wei et al. (2018) used a nitrogen doped carbon (CN) derived from MOF ZIF-8 as support for several noble metals $(\mathrm{Pd}, \mathrm{Pt}, \mathrm{Au})$ [103]. The work reported the transition of nanoparticles to single atom metals at 
high temperature as a function of time, using in situ environmental transmission electron microscopy (ETEM). The prepared catalyst presented enhanced catalytic performance in the semi-hydrogenation of acetylene, confirming the influence of metal support interactions.

Wang et al. (2017) developed a new synthetic method to obtain a single ruthenium site supported on nitrogen-doped porous carbon ( $\mathrm{Ru} \mathrm{SAs} / \mathrm{N}-\mathrm{C})$ using MOF UiO-66 as precursor [104]. Ensuring that the Ru single atoms were stabilized in the interior of pores, the aggregation of the metal particles during pyrolysis was avoided. The obtained catalyst was applied in quinoline hydrogenation reaction (Scheme 10) and revealed improved selectivity compared to a similar material where the metal particles are clusters. Additionally, the authors were able to demonstrate the stability of the Ru SAs/N-C, since TEM images after 5 reaction runs revealed that the atomic dispersion of $\mathrm{Ru}$ atoms remained unchanged.<smiles>[C+]1CCC(Cc2cccc3ncccc23)Nc2ccccc21</smiles>

Scheme 10. Quinoline hydrogenation reaction [104].

In a different approach, Li et al. (2018) developed SAC-based ZIF-8 by incorporating the MOF in a spherical activated carbon structure followed by carbonization [105]. This method resulted in a material with highly dispersed nanoparticles, and the formation of bamboo-like carbon nanotubes on the surface of the spherical particles. The authors concluded that in the acetylene hydrochlorination reaction, the optimized catalyst, 17\% ZIF-8/SAC, promoting the adsorption of hydrogen chloride and acetylene, presented better stability and lower coke formation while displaying an acetylene conversion of $81 \%$.

Starting from a $\mathrm{Zn} /$ Co bimetallic zeolitic imidazolate framework (BIMZIF(Co,Zn)), it was possible to prepare a carbon supported cobalt catalyst with atomically dispersed Co species. This catalyst was used in the hydrogenation of nitroarenes, aiming at reducing the cost associated with the metal while improving selectivity in comparison with the industrially used Pt catalyst. The catalyst revealed both high activity and selectivity in the hydrogenation of industrially relevant nitroarenes toward their corresponding anilines, and even with sterically hindered nitroarene high chemoselectivity was reported [106].

In the upgrade reactions for biomass-derived chemicals and platform molecules, the oxidative esterification of 5-hydroxymethylfurfural (HMF) into dimethyl furan dicarboxylate (DMFDCA) is a relevant transformation related to the polyester synthesis. Fen et al. (2020) reported a Co-based carbon catalyst prepared from the precursor ZIF- 67 with high catalytic performance $(>99 \%$ conversion and $95 \%$ yield) [107]. DFT simulations provided better insight into the mechanism and revealed that molecular oxygen and HMF were adsorbed and activated on C-N sheets. Also, no 2,5-diformylfuran (DFF) was observed indicating the preferential oxidative esterification of aldehyde over the oxidation of hydroxyl group in HMF (Scheme 11).

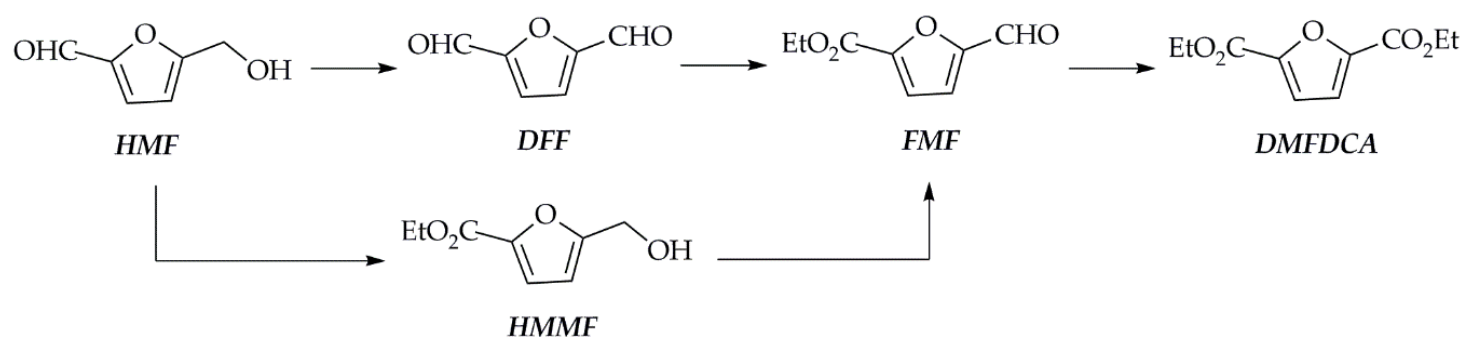

Scheme 11. Reaction pathway for the oxidation esterification of 5-hydroxymethylfurfural (HMF) to dimethyl furan dicarboxylate (DMFDCA) [107]. 
A one-pot sequential Knoevenagel condensation-hydrogenation reaction was catalyzed by a bipyridyl metal-organic framework (MOF-253)-derived carbon catalyst [108]. The Cz-MOF-253 resulting from the MOF-253 pyrolysis revealed to be a solid base catalyst with excellent catalytic efficiency in the Knoevenagel condensation reaction. The material was subsequently modified by incorporating Pd in the surface aiming at bifunctional catalyst for tandem reaction in which Knoevenagel condensation and subsequent hydrogenation of substituted benzaldehyde with malononitrile occurs.

Nanozymes are a class of nanomaterials presenting enzyme-like characteristics that are considered promising alternatives for natural enzymes in various applications. However, much work is still needed to improve these materials performances. SACs may represent an alternative pathway to design functional materials as highly active enzyme-like catalysts. Niu et al. (2019) reported a peroxidase-mimicking nanozyme composed of atomically dispersed $\mathrm{Fe}-\mathrm{Nx}$ moieties over MOF-derived carbon. The nanozyme was prepared by pyrolysis of ZIF-8 Fe doped MOF $\left(900{ }^{\circ} \mathrm{C}, \mathrm{N}_{2}, 2 \mathrm{~h}\right)$ followed by $\mathrm{NH}_{3}$ at $900{ }^{\circ} \mathrm{C}$ for $1 \mathrm{~h}$. The obtained Fe-N-C SAN revealed a specific activity of $57.76 \mathrm{U} \mathrm{mg}^{-1}$, this being value very close to the level of natural horseradish peroxidase (HRP) [109].

\subsection{Other Porous Carbons}

As previously mentioned, single-site cationic Au often evolves sintering of small Au clusters during the acetylene hydrochlorination. In this context, Lan et al. (2020) recently reported an unsuspected phenomenon when investigating Au supported on activated carbon [110]. The authors demonstrated the dynamically evolution of gold nanoparticles to cationic Au single-sites spontaneously dispersed and stabilized on carbon matrix defects occurring during the hydrochlorination process. This study was especially relevant constituting an interesting synthetic approach for designing Au SACs since the metal nanoparticle dispersion on carbon supports is a well-known and developed strategy.

In another context, highly dispersed Pd nanoparticles supported on carbon nanofibers [111] and nitrogen doped carbon nanofibers, Pd/NCNFs, [112] for the selective acetylene hydrogenation have been also investigated. Different metal contents were explored, however, single Pd atoms were formed at the surface when Pd concentration was below $0.2 \mathrm{wt} . \%$ or less, existing as two states with ratio strongly depending on the metal loading and, consequently conditioning the catalytic performance. In the case of $\mathrm{Pd} / \mathrm{NCNFs}$, the presence of porphyrin nucleus at the CNFs surface, among others, favors the stabilization of Pd atoms. In the same context, Feng et al. (2019) developed a catalyst, in which atomic Pd is $\mathrm{N}$-coordinatively bound on the inner walls of mesoporous nitrogen-doped carbon foam nanospheres (ISA-Pd/MPNC), following a hard-template Lewis acid doping approach using polyaniline as nitrogen precursor [113]. This SAC with thin pore walls ranging $1-2 \mathrm{~nm}$ and high surface area $\left(634 \mathrm{~m}^{2} / \mathrm{g}\right)$ resulted in high catalytic activity and excellent selectivity in the semi-hydrogenation of acetylene to ethylene.

Single-atom sites metals ( $\mathrm{Fe}, \mathrm{Co}, \mathrm{Ni}) /$ nitrogen-doped porous carbons, prepared from metal salts and dopamine, by polymerization in alkaline medium followed by pyrolysis, using a top-down polymerization-pyrolysis etching-activation (PPEA) approach, as highly efficient and selective (up to $99 \%$ to phenol) catalysts for benzene oxidation have been recently reported [114].

In continuation within the scope of hydrogenation reactions, Liu et al. (2018) reported an ultradurable and reusable Ni SAC with high hydrothermal stability useful in hydrogenation of biomass-bearing unsaturated groups, under mild reaction conditions, showing an excellent catalytic activity for the hydrogenation of nitroarenes and unsaturated compounds such as styrene, phenylacetylene, among others [115]. The catalyst was prepared from $\mathrm{Ni}(\mathrm{phen})_{3}$ dispersed on $\mathrm{MgO}$ and subsequently pyrolyzed at $600{ }^{\circ} \mathrm{C}$ in $\mathrm{N}_{2}$ atmosphere, the initial $\mathrm{MgO}$ support being removed by acid etching. This Ni SAC presented high Ni loading ( $7.5 \mathrm{wt} . \%)$ in which $\mathrm{Ni}$ is covalently bound to $\mathrm{N}$ atoms, the catalytic active sites comprising $\left(\mathrm{Ni}-\mathrm{N}_{4}\right)-\mathrm{N}$. The authors experimentally confirmed the involvement of Lewis basic sites in the nitroarenes hydrogenation. In the same context, some of these authors used a similar synthetic strategy to prepare a Co SAC exhibiting an excellent catalytic 
performance in the hydrogenative coupling of nitroarenes chemioselectively yielding the corresponding azo compounds [116] (Scheme 12).<smiles>O=[N+]([O-])c1ccccc1</smiles>

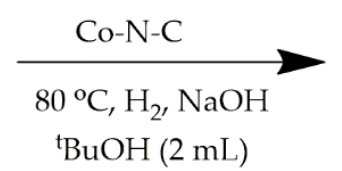<smiles>[R]c1ccc(/N=N/c2ccc([R])cc2)cc1</smiles>

$(63-99 \%)$

Scheme 12. Nitroarene coupling catalyzed by Co single-atom catalyst (SAC) [116].

Much more recently, Long et al. (2020) developed an atomically Fe dispersed on phosphorus doped porous carbon active in hydrogenation of nitroarenes, $\mathrm{N}$-heterocycles such as quinolines, and reductive amination reactions [117]. The synthetic strategy consisted of using $\mathrm{Fe}$ impregnated $\mathrm{SiO}_{2}$ nanoparticles, $\mathrm{SiO}_{2}$ as sacrificial hard template and sucrose and phytic acid as carbon and phosphorous precursors, and pyrolyzed at different temperatures from 700 to $1100{ }^{\circ} \mathrm{C}$. The authors attributed the excellent catalytic activity and selectivity to the presence of $\mathrm{Fe}-\mathrm{P}_{4}$ sites, in situ generated by reduction of initial $\mathrm{O}_{2}-\mathrm{Fe}-\mathrm{P}_{4}$ species, demonstrating that $\mathrm{P}_{\text {grap }}$ is key in the hydrogenation reaction. In the same context, metal $(\mathrm{Co}, \mathrm{Fe}, \mathrm{Ni}, \mathrm{Mn}, \mathrm{Cu})$ single atoms tethered on a hierarchical mesoporous $\mathrm{N}$-doped carbon prepared by molten salt assisted method, in the presence of chitosan and melamine as carbon and nitrogen precursors, involved in the selective hydrogenation of bioactive pharmaceuticals such as nimodipine (Scheme 13) or large sized quinolines, $2-\left(3^{\prime}, 4^{\prime}\right.$-methylenedioxyphenylethyl)quinoline (Scheme 14) for instance, have been recently reported [118]. The authors attributed the notably superior catalytic activity mainly to the accessibility of metal sites and to the hierarchical porous structure.<smiles>CCCCCOC(=O)COCCOC(=O)NCCOCCOC(=O)C1=C(C)NC(C)=C(C(=O)OCCOC)C1c1cccc(N)c1</smiles>

Scheme 13. Hydrogenation of nimodipine catalyzed by Co1/h-NC.<smiles>CC(C)NC(=O)CCNC1CCc2ccccc2N1</smiles>

Scheme 14. Hydrogenation of 2-( $3^{\prime}, 4^{\prime}$-methylenedioxyphenylethyl)quinoline catalyzed by Co1/h-NC.

Interestingly, Zhang et al. (2015) reported a recyclable Co-N-C SAC, Co-N-C/CMK-3, synthetized by pyrolysis of cobalt-phenanthroline on a mesoporous carbon, able to catalyze the aerobic oxidative cross-coupling of primary and secondary alcohols to $\alpha, \beta$-unsaturated ketones in almost quantitative yields and also showing an excellent catalytic activity, in which single Co atoms bound to $\mathrm{N}$ in graphitic sheets are the catalytic specie [119] (Scheme 15). 


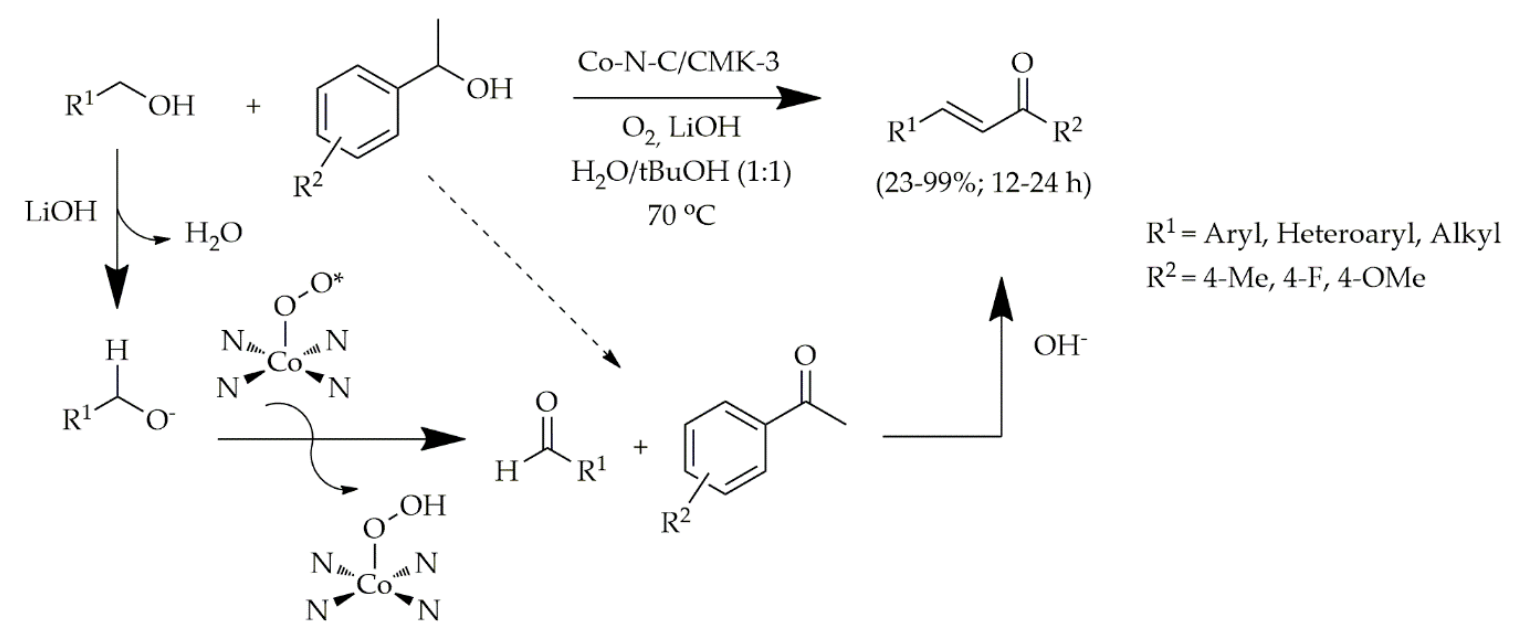

Scheme 15. Aerobic oxidative cross-coupling of primary and secondary alcohols to $\alpha, \beta$-unsaturated ketones catalyzed by Co-N-C/CMK-3 SAC [119].

\section{Conclusions}

One of the challenges in catalysis concerns the development of SACs as a new generation of heterogeneous catalysts and particularly with applications in fine chemical production [32]. SACs share some characteristics with heterogeneous and homogeneous counterparts. However, SACs also present their own individual characteristics, making them catalysts with great potential for the synthesis of highly valuable compounds. Metals atomically dispersed over an appropriate support allow to maximize the efficiency of the metal, conditioning then their catalytic performance. A decrease in nanoparticles or nanoclusters population favoring single atoms can notably alter the reactivity due to changes in the active-site structure. In fact, the great catalytic performance reported for a variety of SACs is mainly attributed to the presence of different coordination environments resulting from the distinct single metal atoms coordination modes in structurally different defects at the support surface. Although diverse experimental and theoretical studies focused on the catalytic behavior of SACs have led to better understanding, many more efforts to achieve a similar knowledge are needed, in this case at the atomic level, as that for organometallic catalysts [120]. Obviously, the morphology, texture and composition of the support matrix are also determinant factors in the development of SACs in order to obtain high density of accessible and active metal atoms. The stability of metal atoms is also key in this type of catalysts, guaranteeing both durability and recyclability [6]. Therefore, strong interactions between metal atoms and the support are crucial.

Considering the unique physico-chemical properties of porous carbons and the possibility of introducing controlled high concentration of defects on its structure, they are ideal supports for the design and synthesis of highly dispersed metal catalysts. Different synthetic strategies and even sophisticated approaches for the preparation of carbon-based SACs have been reported. Among them, the impregnation-thermal treatments by using notably lower metal concentrations to avoid the agglomerates formation, the metal deposition by using CVD or ALD methods, but also the pyrolysis of organometallic compounds or those supported on carbon matrices have been highlighted. The modification of the surface chemistry of the porous carbonaceous support or the pyrolysis of the organometallic compounds are the preferred methods to synthetize stable SACs.

Several carbon supports, such as preferably MWCNT and graphene or even CNF, and to a lesser extent other porous carbons-AC or mesoporous carbons-have been explored in SACs development. Interestingly, MOF-derived carbons using different techniques often result in metal-doped materials, but it is common that more careful synthetic approaches are needed in order to obtain single atom dispersions, preventing the formation of nano particles or aggregates. These materials have been developed mainly for applications such as photocatalysis or electrocatalysis and to a much lesser extent to fine chemical synthesis, where their potential remains to be further explored. In the same context, 
graphyne can also be a promising carbon support for the noble-metal SACs [121], since theoretical studies developed by Ma et al. (2015) showed that the adsorption of single atoms of noble-metal such as $\mathrm{Au}, \mathrm{Pt}, \mathrm{Ir}, \mathrm{Pd}$, among others, is certainly strong at the ring formed by three acetylenic functions in graphyne sheet.

The main goal for the development of SACs is the design of effective strategies guaranteeing stability and hence durability. In general, the thermal treatments should be carefully controlled, since small metal clusters often sinter to bigger nanoparticles, at increased temperatures, due to its thermodynamic stability. Contrarily to that, sintering reversion effects were observed when synthetizing a $N$-doped carbon derived from ZIF-8 at elevated temperatures $\left(900^{\circ} \mathrm{C}\right)$ [103], emphasizing the potential of using MOFs as highly valuable precursors of SACs.

In summary, porous carbon-derived SACs can be considered as a type of new and eco-friendly catalysts with great potential, yet to be explored in terms of both synthesis strategies and activity in a considerable variety of organic transformations, through cascade reactions, involved in the green synthesis of highly valuable compounds.

Author Contributions: Conceptualization, E.P.-M., I.M. and I.M.F.; methodology, E.P.-M. and I.M.; writing —original draft preparation, E.P.-M., I.M., M.B. and M.V.; writing - review and editing, I.M.F.; visualization, E.P.-M., I.M., M.B. and M.V.; supervision, E.P.-M. and I.M.F.; project administration, E.P.-M.; funding acquisition, E.P.-M. and I.M.F. All authors have read and agreed to the published version of the manuscript.

Funding: This work has been supported by Spanish Ministry (CTM 2014-56668-R project) and by the Associate Laboratory for Green Chemistry-LAQV which is financed by national funds from FCT/MCTES (UIDB/50006/2020).

Conflicts of Interest: The authors declare no conflict of interest.

\section{References}

1. Pérez-Mayoral, E.; Calvino-Casilda, V.; Soriano, E. Metal-supported carbon-based materials: Opportunities and challenges in the synthesis of valuable products. Catal. Sci. Technol. 2016, 6, 1265-1291. [CrossRef]

2. Serp, P.; Figueiredo, J.L. Carbon Materials for Catalysis; Serp, P., Figueiredo, J.L., Eds.; John Wiley \& Sons, Inc.: Hoboken, NJ, USA, 2008; ISBN 9780470403709.

3. Pérez-Mayoral, E.; Calvino-Casilda, V.; Godino, M.; López- Peinado, A.J.; Martín-Aranda, R.M. Porous Catalytic Systems in the Synthesis of Bioactive Heterocycles and Related Compounds. In Green Synthetic Approaches for Biologically Relevant Heterocycles; Brahmachari, G., Ed.; Elsevier: Amsterdam, The Netherlands, 2015; pp. 377-408. ISBN 9780128005903.

4. Pérez-Mayoral, E.; Soriano, E.; Martín-Aranda, R.M.; Maldonado-Hódar, F.J. Mesoporous Catalytic Materials and Fine Chemistry. In Comprehensive Guide for Mesoporous Materials. Volume 1: Synthesis and Characterization; Aliofkhazraei, M., Ed.; Nova Science Publishers: Hauppauge, NY, USA, 2015; pp. 83-118. ISBN 978-1-63463-958-3.

5. Matos, I.; Bernardo, M.; Fonseca, I. Porous carbon: A versatile material for catalysis. Catal. Today 2017, 285, 194-203. [CrossRef]

6. Yang, X.-F.; Wang, A.; Qiao, B.; Li,J.; Liu, J.; Zhang, T. Single-Atom Catalysts: A New Frontier in Heterogeneous Catalysis. Acc. Chem. Res. 2013, 46, 1740-1748. [CrossRef]

7. Liu, L.; Corma, A. Metal Catalysts for Heterogeneous Catalysis: From Single Atoms to Nanoclusters and Nanoparticles. Chem. Rev. 2018, 118, 4981-5079. [CrossRef] [PubMed]

8. Kou, Z.; Zang, W.; Wang, P.; Li, X.; Wang, J. Single atom catalysts: A surface heterocompound perspective. Nanoscale Horiz. 2020, 5, 757-764. [CrossRef]

9. Christopher, P. Single-Atom Catalysts: Are All Sites Created Equal? ACS Energy Lett. 2019, 4, 2249-2250. [CrossRef]

10. Liu, J. Catalysis by Supported Single Metal Atoms. ACS Catal. 2017, 7, 34-59. [CrossRef]

11. Haruta, M. Gold catalysts prepared by coprecipitation for low-temperature oxidation of hydrogen and of carbon monoxide. J. Catal. 1989, 115, 301-309. [CrossRef]

12. Papp, C. Catalysis at the limit. Nat. Chem. 2018, 10, 995-996. [CrossRef] 
13. Wang, A.; Li, J.; Zhang, T. Heterogeneous single-atom catalysis. Nat. Rev. Chem. 2018, 2, 65-81. [CrossRef]

14. He, T.; Chen, S.; Ni, B.; Gong, Y.; Wu, Z.; Song, L.; Gu, L.; Hu, W.; Wang, X. Zirconium-Porphyrin-Based Metal-Organic Framework Hollow Nanotubes for Immobilization of Noble-Metal Single Atoms. Angew. Chem. Int. Ed. 2018, 57, 3493-3498. [CrossRef] [PubMed]

15. Liu, L.; Díaz, U.; Arenal, R.; Agostini, G.; Concepción, P.; Corma, A. Generation of subnanometric platinum with high stability during transformation of a 2D zeolite into 3D. Nat. Mater. 2017, 16, 132-138. [CrossRef]

16. Ortalan, V.; Uzun, A.; Gates, B.C.; Browning, N.D. Direct imaging of single metal atoms and clusters in the pores of dealuminated HY zeolite. Nat. Nanotechnol. 2010, 5, 506-510. [CrossRef]

17. Cheng, N.; Zhang, L.; Doyle-Davis, K.; Sun, X. Single-Atom Catalysts: From Design to Application. Electrochem. Energy Rev. 2019, 2, 539-573. [CrossRef]

18. Rivera-Cárcamo, C.; Serp, P. Single Atom Catalysts on Carbon-Based Materials. ChemCatChem 2018, 10, 5058-5091. [CrossRef]

19. Gawande, M.B.; Fornasiero, P.; Zbořil, R. Carbon-Based Single-Atom Catalysts for Advanced Applications. ACS Catal. 2020, 10, 2231-2259. [CrossRef]

20. Chen, Y.; Zhang, X.; Zhou, Z. Carbon-Based Substrates for Highly Dispersed Nanoparticle and Even Single-Atom Electrocatalysts. Small Methods 2019, 3, 1900050. [CrossRef]

21. Li, J.-C.; Wei, Z.; Liu, D.; Du, D.; Lin, Y.; Shao, M. Dispersive Single-Atom Metals Anchored on Functionalized Nanocarbons for Electrochemical Reactions. Top. Curr. Chem. 2019, 377, 4. [CrossRef] [PubMed]

22. Tiwari, J.N.; Dang, N.K.; Park, H.J.; Sultan, S.; Kim, M.G.; Haiyan, J.; Lee, Z.; Kim, K.S. Remarkably enhanced catalytic activity by the synergistic effect of palladium single atoms and palladium-cobalt phosphide nanoparticles. Nano Energy 2020, 78, 105166. [CrossRef]

23. Cao, L.; Luo, Q.; Liu, W.; Lin, Y.; Liu, X.; Cao, Y.; Zhang, W.; Wu, Y.; Yang, J.; Yao, T.; et al. Identification of single-atom active sites in carbon-based cobalt catalysts during electrocatalytic hydrogen evolution. Nat. Catal. 2019, 2, 134-141. [CrossRef]

24. Liu, Q.; Peng, Y.; Li, Q.; He, T.; Morris, D.; Nichols, F.; Mercado, R.; Zhang, P.; Chen, S. Atomic Dispersion and Surface Enrichment of Palladium in Nitrogen-Doped Porous Carbon Cages Lead to High-Performance Electrocatalytic Reduction of Oxygen. ACS Appl. Mater. Interfaces 2020, 12, 17641-17650. [CrossRef] [PubMed]

25. Arrigo, R.; Schuster, M. On the High Structural Heterogeneity of Fe-Impregnated Graphitic-Carbon Catalysts from Fe Nitrate Precursor. Catalysts 2019, 9, 303. [CrossRef]

26. Carlier, S.; Gripekoven, J.; Philippo, M.; Hermans, S. Ru on N-doped carbon supports for the direct hydrogenation of cellobiose into sorbitol. Appl. Catal. B Environ. 2021, 282, 119515. [CrossRef]

27. Lu, Y.; Wang, H.; Yu, P.; Yuan, Y.; Shahbazian-Yassar, R.; Sheng, Y.; Wu, S.; Tu, W.; Liu, G.; Kraft, M.; et al. Isolated $\mathrm{Ni}$ single atoms in nitrogen doped ultrathin porous carbon templated from porous $g-\mathrm{C}_{3} \mathrm{~N}_{4}$ for high-performance $\mathrm{CO}_{2}$ reduction. Nano Energy 2020, 77, 105158. [CrossRef]

28. Yu, Y.; Yang, S.; Dou, M.; Zhang, Z.; Wang, F. Photochemically activated atomic ruthenium supported on boron-doped carbon as a robust electrocatalyst for hydrogen evolution. J. Mater. Chem. A 2020, 8, 16669-16675. [CrossRef]

29. Jin, H.; Sultan, S.; Ha, M.; Tiwari, J.N.; Kim, M.G.; Kim, K.S. Simple and Scalable Mechanochemical Synthesis of Noble Metal Catalysts with Single Atoms toward Highly Efficient Hydrogen Evolution. Adv. Funct. Mater. 2020, 30, 2000531. [CrossRef]

30. Jeon, I.-Y.; Kim, S.-W.; Shin, S.-H.; Jung, S.-M.; Baek, J.-B. Forming indium-carbon (In-C) bonds at the edges of graphitic nanoplatelets. Mater. Today Adv. 2020, 6, 100030. [CrossRef]

31. Yan, J.; Tian, X.; Liu, X.-Y.; Zhao, X.; Wang, R.; Zhao, L.-J.; Zhang, X. Correlation between electrochemical properties of the $\mathrm{CNTs} / \mathrm{AB}_{5}$ composite hydrogen storage alloys and their catalytic properties for $\mathrm{KBH}_{4}$. Int. J. Hydrogen Energy 2020, 45, 452-463. [CrossRef]

32. Zhang, L.; Ren, Y.; Liu, W.; Wang, A.; Zhang, T. Single-atom catalyst: A rising star for green synthesis of fine chemicals. Natl. Sci. Rev. 2018, 5, 653-672. [CrossRef]

33. Li, X.; Lei, H.; Guo, X.; Zhao, X.; Ding, S.; Gao, X.; Zhang, W.; Cao, R. Graphene-Supported Pyrene-Modified Cobalt Corrole with Axial Triphenylphosphine for Enhanced Hydrogen Evolution in pH 0-14 Aqueous Solutions. ChemSusChem 2017, 10, 4632-4641. [CrossRef] 
34. Kharisov, B.I.; Kharissova, O.V.; Vázquez Dimas, A.; Gómez De La Fuente, I.; Peña Méndez, Y. Review: Graphene-supported coordination complexes and organometallics: Properties and applications. J. Coord. Chem. 2016, 69, 1125-1151. [CrossRef]

35. Campisciano, V.; Gruttadauria, M.; Giacalone, F. Modified Nanocarbons for Catalysis. ChemCatChem 2019, 11, 90-133. [CrossRef]

36. Choi, B.; Lee, J.; Lee, S.; Ko, J.-H.; Lee, K.-S.; Oh, J.; Han, J.; Kim, Y.-H.; Choi, I.S.; Park, S. Generation of Ultra-High-Molecular-Weight Polyethylene from Metallocenes Immobilized onto N-Doped Graphene Nanoplatelets. Macromol. Rapid Commun. 2013, 34, 533-538. [CrossRef]

37. Su, H.; Wu, S.; Li, Z.; Huo, Q.; Guan, J.; Kan, Q. Co(II), Fe(III) or VO(II) Schiff base metal complexes immobilized on graphene oxide for styrene epoxidation. Appl. Organomet. Chem. 2015, 29, 462-467. [CrossRef]

38. Sabounchei, S.J.; Hosseinzadeh, M.; Zarepour-jevinani, M.; Ghanbari, B. Monodentate palladium(0)-[60]fullerene complexes of diphosphine ligands as efficient and sustainable nanocatalysts for the Mizoroki-Heck coupling reaction of aryl chlorides. New J. Chem. 2017, 41, 9701-9709. [CrossRef]

39. Kumar, R.; Gravel, E.; Hagège, A.; Li, H.; Jawale, D.V.; Verma, D.; Namboothiri, I.N.N.; Doris, E. Carbon nanotube-gold nanohybrids for selective catalytic oxidation of alcohols. Nanoscale 2013, 5, 6491. [CrossRef]

40. Queffélec, C.; Schlindwein, S.H.; Gudat, D.; Silvestre, V.; Rodriguez-Zubiri, M.; Fayon, F.; Bujoli, B.; Wang, Q.; Boukherroub, R.; Szunerits, S. Wilkinson-Type Immobilized Catalyst on Diamond Nanoparticles for Alkene Reduction. ChemCatChem 2017, 9, 432-439. [CrossRef]

41. Ribeiro, A.P.C.; Martins, L.M.D.R.S.; Carabineiro, S.A.C.; Buijnsters, J.G.; Figueiredo, J.L.; Pombeiro, A.J.L. Heterogenized C-Scorpionate Iron(II) Complex on Nanostructured Carbon Materials as Recyclable Catalysts for Microwave-Assisted Oxidation Reactions. ChemCatChem 2018, 10, 1821-1828. [CrossRef]

42. Pour, S.R.; Abdolmaleki, A.; Dinari, M. Immobilization of new macrocyclic Schiff base copper complex on graphene oxide nanosheets and its catalytic activity for olefins epoxidation. J. Mater. Sci. 2019, 54, 2885-2896. [CrossRef]

43. Ren, R.; Bi, S.; Wang, L.; Zhao, W.; Wei, D.; Li, T.; Xu, W.; Liu, M.; Wu, Y. Terpyridine-based Pd(II)/Ni(II) organometallic framework nano-sheets supported on graphene oxide-Investigating the fabrication, tuning of catalytic properties and synergetic effects. RSC Adv. 2020, 10, 23080-23090. [CrossRef]

44. Sánchez-Page, B.; Pérez-Mas, A.M.; González-Ingelmo, M.; Fernández, L.; González, Z.; Jiménez, M.V.; Pérez-Torrente, J.J.; Blasco, J.; Subías, G.; Álvarez, P.; et al. Influence of graphene sheet properties as supports of iridium-based N-heterocyclic carbene hybrid materials for water oxidation electrocatalysis. J. Organomet. Chem. 2020, 919, 121334. [CrossRef]

45. Serp, P.; Kalck, P.; Feurer, R. Chemical Vapor Deposition Methods for the Controlled Preparation of Supported Catalytic Materials. Chem. Rev. 2002, 102, 3085-3128. [CrossRef]

46. Zhang, L.; Wang, Y.; Niu, Z.; Chen, J. Single Atoms on Graphene for Energy Storage and Conversion. Small Methods 2019, 3, 1800443. [CrossRef]

47. Sun, S.; Zhang, G.; Gauquelin, N.; Chen, N.; Zhou, J.; Yang, S.; Chen, W.; Meng, X.; Geng, D.; Banis, M.N.; et al. Single-atom Catalysis Using Pt/Graphene Achieved through Atomic Layer Deposition. Sci. Rep. 2013, 3, 1775. [CrossRef]

48. Wang, Y.; Mao, J.; Meng, X.; Yu, L.; Deng, D.; Bao, X. Catalysis with Two-Dimensional Materials Confining Single Atoms: Concept, Design, and Applications. Chem. Rev. 2019, 119, 1806-1854. [CrossRef]

49. Han, X.; Sun, W.; Zhao, C.; Shi, R.; Wang, X.; Liu, S.; Li, Z.; Ren, J. Synthesis of dimethyl carbonate on single $\mathrm{Cu}$ atom embedded in $\mathrm{N}$-doped graphene: Effect of nitrogen species. Mol. Catal. 2017, 443, 1-13. [CrossRef]

50. Du, P.; Hu, K.; Lyu, J.; Li, H.; Lin, X.; Xie, G.; Liu, X.; Ito, Y.; Qiu, H.-J. Anchoring Mo single atoms/clusters and $\mathrm{N}$ on edge-rich nanoporous holey graphene as bifunctional air electrode in $\mathrm{Zn}$-air batteries. Appl. Catal. B Environ. 2020, 276, 119172. [CrossRef]

51. O'Neill, B.J.; Jackson, D.H.K.; Lee, J.; Canlas, C.; Stair, P.C.; Marshall, C.L.; Elam,J.W.; Kuech, T.F.; Dumesic, J.A.; Huber, G.W. Catalyst Design with Atomic Layer Deposition. ACS Catal. 2015, 5, 1804-1825. [CrossRef]

52. Huang, X.; Xia, Y.; Cao, Y.; Zheng, X.; Pan, H.; Zhu, J.; Ma, C.; Wang, H.; Li, J.; You, R.; et al. Enhancing both selectivity and coking-resistance of a single-atom $\mathrm{Pd} 1 / \mathrm{C}_{3} \mathrm{~N}_{4}$ catalyst for acetylene hydrogenation. Nano Res. 2017, 10, 1302-1312. [CrossRef] 
53. Yan, H.; Cheng, H.; Yi, H.; Lin, Y.; Yao, T.; Wang, C.; Li, J.; Wei, S.; Lu, J. Single-Atom Pd ${ }_{1} / G^{-} \operatorname{laphene}$ Catalyst Achieved by Atomic Layer Deposition: Remarkable Performance in Selective Hydrogenation of 1,3-Butadiene. J. Am. Chem. Soc. 2015, 137, 10484-10487. [CrossRef]

54. Li, Z.; Ge, R.; Su, J.; Chen, L. Recent Progress in Low Pt Content Electrocatalysts for Hydrogen Evolution Reaction. Adv. Mater. Interfaces 2020, 7, 2000396. [CrossRef]

55. Nayak, P.; Jiang, Q.; Kurra, N.; Wang, X.; Buttner, U.; Alshareef, H.N. Monolithic laser scribed graphene scaffolds with atomic layer deposited platinum for the hydrogen evolution reaction. J. Mater. Chem. A 2017, 5, 20422-20427. [CrossRef]

56. Zhang, Z.; Deng, L.; Zhao, Z.; Zhao, Y.; Yang, J.; Jiang, J.; Huang, G.; Mei, Y. Nickel nanograins anchored on a carbon framework for an efficient hydrogen evolution electrocatalyst and a flexible electrode. J. Mater. Chem. A 2020, 8, 3499-3508. [CrossRef]

57. Liang, Z.; Qu, C.; Xia, D.; Zou, R.; Xu, Q. Atomically Dispersed Metal Sites in MOF-Based Materials for Electrocatalytic and Photocatalytic Energy Conversion. Angew. Chemie Int. Ed. 2018, 57, 9604-9633. [CrossRef]

58. Niu, S.; Yang, J.; Qi, H.; Su, Y.; Wang, Z.; Qiu, J.; Wang, A.; Zhang, T. Single-atom Pt promoted $\mathrm{Mo}_{2} \mathrm{C}$ for electrochemical hydrogen evolution reaction. J. Energy Chem. 2020. [CrossRef]

59. Hu, X.; Luo, G.; Zhao, Q.; Wu, D.; Yang, T.; Wen, J.; Wang, R.; Xu, C.; Hu, N. Ru Single Atoms on N-Doped Carbon by Spatial Confinement and Ionic Substitution Strategies for High-Performance $\mathrm{Li}-\mathrm{O}_{2}$ Batteries. J. Am. Chem. Soc. 2020, 142, 16776-16786. [CrossRef]

60. Hou, Y.; Liang, Y.-L.; Shi, P.-C.; Huang, Y.-B.; Cao, R. Atomically dispersed Ni species on N-doped carbon nanotubes for electroreduction of $\mathrm{CO}_{2}$ with nearly $100 \%$ CO selectivity. Appl. Catal. B Environ. 2020, 271, 118929. [CrossRef]

61. Wang, H.; Wang, Y.; Li, Y.; Lan, X.; Ali, B.; Wang, T. Highly Efficient Hydrogenation of Nitroarenes by N-Doped Carbon-Supported Cobalt Single-Atom Catalyst in Ethanol/Water Mixed Solvent. ACS Appl. Mater. Interfaces 2020, 12, 34021-34031. [CrossRef]

62. Chen, X.; Ma, D.-D.; Chen, B.; Zhang, K.; Zou, R.; Wu, X.-T.; Zhu, Q.-L. Metal-organic framework-derived mesoporous carbon nanoframes embedded with atomically dispersed Fe-N active sites for efficient bifunctional oxygen and carbon dioxide electroreduction. Appl. Catal. B Environ. 2020, 267, 118720. [CrossRef]

63. Han, S.-G.; Ma, D.-D.; Zhou, S.-H.; Zhang, K.; Wei, W.-B.; Du, Y.; Wu, X.-T.; Xu, Q.; Zou, R.; Zhu, Q.-L. Fluorine-tuned single-atom catalysts with dense surface $\mathrm{Ni}_{4} \mathrm{~N}_{4}$ sites on ultrathin carbon nanosheets for efficient $\mathrm{CO}_{2}$ electroreduction. Appl. Catal. B Environ. 2021, 283, 119591. [CrossRef]

64. Yang, J.; Wang, Z.; Jiang, J.; Chen, W.; Liao, F.; Ge, X.; Zhou, X.; Chen, M.; Li, R.; Xue, Z.; et al. In-situ polymerization induced atomically dispersed manganese sites as cocatalyst for $\mathrm{CO}_{2}$ photoreduction into synthesis gas. Nano Energy 2020, 76, 105059. [CrossRef]

65. Ma, R.; Lin, G.; Ju, Q.; Tang, W.; Chen, G.; Chen, Z.; Liu, Q.; Yang, M.; Lu, Y.; Wang, J. Edge-sited Fe-N 4 atomic species improve oxygen reduction activity via boosting $\mathrm{O}_{2}$ dissociation. Appl. Catal. B Environ. 2020, 265, 118593. [CrossRef]

66. Wang, Y.; Jin, M.; Zhang, X.; Zhao, C.; Wang, H.; Li, S.; Liu, Z. Direct Conversion of Biomass into Compact Air Electrode with Atomically Dispersed Oxygen and Nitrogen Coordinated Copper Species for Flexible Zinc-Air Batteries. ACS Appl. Energy Mater. 2019, 2, 8659-8666. [CrossRef]

67. Bacsa, R.R.; Cameán, I.; Ramos, A.; Garcia, A.B.; Tishkova, V.; Bacsa, W.S.; Gallagher, J.R.; Miller, J.T.; Navas, H.; Jourdain, V.; et al. Few layer graphene synthesis on transition metal ferrite catalysts. Carbon N. Y. 2015, 89, 350-360. [CrossRef]

68. Philippe, R.; Morançais, A.; Corrias, M.; Caussat, B.; Kihn, Y.; Kalck, P.; Plee, D.; Gaillard, P.; Bernard, D.; Serp, P. Catalytic Production of Carbon Nanotubes by Fluidized-Bed CVD. Chem. Vap. Depos. 2007, 13, 447-457. [CrossRef]

69. John, J.; Gravel, E.; Hagège, A.; Li, H.; Gacoin, T.; Doris, E. Catalytic Oxidation of Silanes by Carbon Nanotube-Gold Nanohybrids. Angew. Chemie Int. Ed. 2011, 50, 7533-7536. [CrossRef]

70. Corma, A.; Concepción, P.; Boronat, M.; Sabater, M.J.; Navas, J.; Yacaman, M.J.; Larios, E.; Posadas, A.; López-Quintela, M.A.; Buceta, D.; et al. Exceptional oxidation activity with size-controlled supported gold clusters of low atomicity. Nat. Chem. 2013, 5, 775-781. [CrossRef] 
71. Zhang, F.; Jiao, F.; Pan, X.; Gao, K.; Xiao, J.; Zhang, S.; Bao, X. Tailoring the Oxidation Activity of Pt Nanoclusters via Encapsulation. ACS Catal. 2015, 5, 1381-1385. [CrossRef]

72. Lee, E.-K.; Park, S.-A.; Woo, H.; Hyun Park, K.; Kang, D.W.; Lim, H.; Kim, Y.-T. Platinum single atoms dispersed on carbon nanotubes as reusable catalyst for Suzuki coupling reaction. J. Catal. 2017, 352, 388-393. [CrossRef]

73. Woo, H.; Lee, E.-K.; Yun, S.-W.; Park, S.-A.; Park, K.H.; Kim, Y.-T. Platinum Single Atoms on Carbon Nanotubes as Efficient Catalyst for Hydroalkoxylation. Bull. Korean Chem. Soc. 2017, 38, 1221-1225. [CrossRef]

74. Grasseschi, D.; Silva, W.C.; Souza Paiva, R.d.; Starke, L.D.; do Nascimento, A.S. Surface coordination chemistry of graphene: Understanding the coordination of single transition metal atoms. Coord. Chem. Rev. 2020, 422, 213469. [CrossRef]

75. Deng, D.; Chen, X.; Yu, L.; Wu, X.; Liu, Q.; Liu, Y.; Yang, H.; Tian, H.; Hu, Y.; Du, P.; et al. A single iron site confined in a graphene matrix for the catalytic oxidation of benzene at room temperature. Sci. Adv. 2015, 1, e1500462. [CrossRef]

76. Bakandritsos, A.; Kadam, R.G.; Kumar, P.; Zoppellaro, G.; Medved', M.; Tuček, J.; Montini, T.; Tomanec, O.; Andrýsková, P.; Drahoš, B.; et al. Mixed-Valence Single-Atom Catalyst Derived from Functionalized Graphene. Adv. Mater. 2019, 31, 1900323. [CrossRef]

77. Sun, X.; Han, P.; Li, B.; Zhao, Z. Tunable Catalytic Performance of Single Pt Atom on Doped Graphene in Direct Dehydrogenation of Propane by Rational Doping: A Density Functional Theory Study. J. Phys. Chem. C 2018, 122, 1570-1576. [CrossRef]

78. Li, M.; Wu, S.; Yang, X.; Hu, J.; Peng, L.; Bai, L.; Huo, Q.; Guan, J. Highly efficient single atom cobalt catalyst for selective oxidation of alcohols. Appl. Catal. A Gen. 2017, 543, 61-66. [CrossRef]

79. Liu, X.; Yang, Y.; Chu, M.; Duan, T.; Meng, C.; Han, Y. Defect stabilized gold atoms on graphene as potential catalysts for ethylene epoxidation: A first-principles investigation. Catal. Sci. Technol. 2016, 6, 1632-1641. [CrossRef]

80. Wang, S.; Liu, Y.; Zhao, J. PtN $\mathrm{Pt}_{3}$-Embedded graphene as an efficient catalyst for electrochemical reduction of nitrobenzene to aniline: A theoretical study. Phys. Chem. Chem. Phys. 2020, 22, 17639-17645. [CrossRef]

81. Lou, Y.; Wu, H.; Liu, J. Nanocarbon-Edge-Anchored High-Density Pt Atoms for 3-nitrostyrene Hydrogenation: Strong Metal-Carbon Interaction. iScience 2019, 13, 190-198. [CrossRef]

82. Huang, H.; Wang, X.; Sheng, Y.; Chen, C.; Zou, X.; Shang, X.; Lu, X. Nitrogen-doped graphene-activated metallic nanoparticle-incorporated ordered mesoporous carbon nanocomposites for the hydrogenation of nitroarenes. RSC Adv. 2018, 8, 8898-8909. [CrossRef]

83. Xi, J.; Sun, H.; Wang, D.; Zhang, Z.; Duan, X.; Xiao, J.; Xiao, F.; Liu, L.; Wang, S. Confined-interface-directed synthesis of Palladium single-atom catalysts on graphene/amorphous carbon. Appl. Catal. B Environ. 2018, 225, 291-297. [CrossRef]

84. Yan, H.; Lv, H.; Yi, H.; Liu, W.; Xia, Y.; Huang, X.; Huang, W.; Wei, S.; Wu, X.; Lu, J. Understanding the underlying mechanism of improved selectivity in pd1 single-atom catalyzed hydrogenation reaction. J. Catal. 2018, 366, 70-79. [CrossRef]

85. Almeida Ribeiro, R.S.; Monteiro Ferreira, L.E.; Rossa, V.; Lima, C.G.S.; Paixão, M.W.; Varma, R.S.; Melo Lima, T. Graphitic Carbon Nitride-Based Materials as Catalysts for the Upgrading of Lignocellulosic Biomass-Derived Molecules. ChemSusChem 2020, 13, 3992-4004. [CrossRef]

86. Verma, S.; Nadagouda, M.N.; Varma, R.S. Porous nitrogen-enriched carbonaceous material from marine waste: Chitosan-derived carbon nitride catalyst for aerial oxidation of 5-hydroxymethylfurfural (HMF) to 2,5-furandicarboxylic acid. Sci. Rep. 2017, 7, 13596. [CrossRef]

87. Liu, J.; Wang, H.; Antonietti, M. Graphitic carbon nitride "reloaded": Emerging applications beyond (photo)catalysis. Chem. Soc. Rev. 2016, 45, 2308-2326. [CrossRef]

88. Huang, J.; Antonietti, M.; Liu, J. Bio-inspired carbon nitride mesoporous spheres for artificial photosynthesis: Photocatalytic cofactor regeneration for sustainable enzymatic synthesis. J. Mater. Chem. A 2014, 2, 7686-7693. [CrossRef]

89. Yang, S.; Gong, Y.; Zhang, J.; Zhan, L.; Ma, L.; Fang, Z.; Vajtai, R.; Wang, X.; Ajayan, P.M. Exfoliated Graphitic Carbon Nitride Nanosheets as Efficient Catalysts for Hydrogen Evolution Under Visible Light. Adv. Mater. 2013, 25, 2452-2456. [CrossRef] 
90. Mishra, A.; Mehta, A.; Basu, S.; Shetti, N.P.; Reddy, K.R.; Aminabhavi, T.M. Graphitic carbon nitride $\left(\mathrm{g}-\mathrm{C}_{3} \mathrm{~N}_{4}\right)$-based metal-free photocatalysts for water splitting: A review. Carbon N. Y. 2019, 149, 693-721. [CrossRef]

91. Shalom, M.; Gimenez, S.; Schipper, F.; Herraiz-Cardona, I.; Bisquert, J.; Antonietti, M. Controlled Carbon Nitride Growth on Surfaces for Hydrogen Evolution Electrodes. Angew. Chemie 2014, 126, 3728-3732. [CrossRef]

92. Zhou, Z.; Zhang, Y.; Shen, Y.; Liu, S.; Zhang, Y. Molecular engineering of polymeric carbon nitride: Advancing applications from photocatalysis to biosensing and more. Chem. Soc. Rev. 2018, 47, 2298-2321. [CrossRef]

93. Dai, B.; Li, X.; Zhang, J.; Yu, F.; Zhu, M. Application of mesoporous carbon nitride as a support for an Au catalyst for acetylene hydrochlorination. Chem. Eng. Sci. 2015, 135, 472-478. [CrossRef]

94. Chen, Z.; Vorobyeva, E.; Mitchell, S.; Fako, E.; López, N.; Collins, S.M.; Leary, R.K.; Midgley, P.A.; Hauert, R.; Pérez-Ramírez, J. Single-atom heterogeneous catalysts based on distinct carbon nitride scaffolds. Natl. Sci. Rev. 2018, 5, 642-652. [CrossRef]

95. Chen, Z.; Mitchell, S.; Krumeich, F.; Hauert, R.; Yakunin, S.; Kovalenko, M.V.; Pérez-Ramírez, J. Tunability and Scalability of Single-Atom Catalysts Based on Carbon Nitride. ACS Sustain. Chem. Eng. 2019, 7, 5223-5230. [CrossRef]

96. Büchele, S.; Chen, Z.; Mitchell, S.; Hauert, R.; Krumeich, F.; Pérez-Ramírez, J. Tailoring Nitrogen-Doped Carbons as Hosts for Single-Atom Catalysts. Chem CatChem 2019, 11, 2812-2820. [CrossRef]

97. Chen, J.; Ge, Y.; Guo, Y.; Chen, J. Selective hydrogenation of biomass-derived 5-hydroxymethylfurfural using palladium catalyst supported on mesoporous graphitic carbon nitride. J. Energy Chem. 2018, 27, 283-289. [CrossRef]

98. Tian, S.; Wang, Z.; Gong, W.; Chen, W.; Feng, Q.; Xu, Q.; Chen, C.; Chen, C.; Peng, Q.; Gu, L.; et al. Temperature-Controlled Selectivity of Hydrogenation and Hydrodeoxygenation in the Conversion of Biomass Molecule by the Ru1/mpg- $\mathrm{C}_{3} \mathrm{~N}_{4}$ Catalyst. J. Am. Chem. Soc. 2018, 140, 11161-11164. [CrossRef]

99. Tian, S.; Gong, W.; Chen, W.; Lin, N.; Zhu, Y.; Feng, Q.; Xu, Q.; Fu, Q.; Chen, C.; Luo, J.; et al. Regulating the Catalytic Performance of Single-Atomic-Site Ir Catalyst for Biomass Conversion by Metal-Support Interactions. ACS Catal. 2019, 9, 5223-5230. [CrossRef]

100. Chen, Z.; Vorobyeva, E.; Mitchell, S.; Fako, E.; Ortuño, M.A.; López, N.; Collins, S.M.; Midgley, P.A.; Richard, S.; Vilé, G.; et al. A heterogeneous single-atom palladium catalyst surpassing homogeneous systems for Suzuki coupling. Nat. Nanotechnol. 2018, 13, 702-707. [CrossRef]

101. Kharissova, O.V.; Kharisov, B.I.; Ulyand, I.E.; García, T.H. Catalysis using metal-organic framework-derived nanocarbons: Recent trends. J. Mater. Res. 2020, 35, 2190-2207. [CrossRef]

102. Han, A.; Wang, B.; Kumar, A.; Qin, Y.; Jin, J.; Wang, X.; Yang, C.; Dong, B.; Jia, Y.; Liu, J.; et al. Recent Advances for MOF-Derived Carbon-Supported Single-Atom Catalysts. Small Methods 2019, 3, 1800471. [CrossRef]

103. Wei, S.; Li, A.; Liu, J.-C.; Li, Z.; Chen, W.; Gong, Y.; Zhang, Q.; Cheong, W.-C.; Wang, Y.; Zheng, L.; et al. Direct observation of noble metal nanoparticles transforming to thermally stable single atoms. Nat. Nanotechnol. 2018, 13, 856-861. [CrossRef]

104. Wang, X.; Chen, W.; Zhang, L.; Yao, T.; Liu, W.; Lin, Y.; Ju, H.; Dong, J.; Zheng, L.; Yan, W.; et al. Uncoordinated Amine Groups of Metal-Organic Frameworks to Anchor Single Ru Sites as Chemoselective Catalysts toward the Hydrogenation of Quinoline. J. Am. Chem. Soc. 2017, 139, 9419-9422. [CrossRef]

105. Li, X.; Zhang, J.; Han, Y.; Zhu, M.; Shang, S.; Li, W. MOF-derived various morphologies of N-doped carbon composites for acetylene hydrochlorination. J. Mater. Sci. 2018, 53, 4913-4926. [CrossRef]

106. Sun, X.; Olivos-Suarez, A.I.; Osadchii, D.; Romero, M.J.V.; Kapteijn, F.; Gascon, J. Single cobalt sites in mesoporous $\mathrm{N}$-doped carbon matrix for selective catalytic hydrogenation of nitroarenes. J. Catal. 2018, 357, 20-28. [CrossRef]

107. Feng, Y.; Jia, W.; Yan, G.; Zeng, X.; Sperry, J.; Xu, B.; Sun, Y.; Tang, X.; Lei, T.; Lin, L. Insights into the active sites and catalytic mechanism of oxidative esterification of 5-hydroxymethylfurfural by metal-organic frameworks-derived N-doped carbon. J. Catal. 2020, 381, 570-578. [CrossRef]

108. Li, X.; Zhang, B.; Fang, Y.; Sun, W.; Qi, Z.; Pei, Y.; Qi, S.; Yuan, P.; Luan, X.; Goh, T.W.; et al. Metal-Organic-Framework-Derived Carbons: Applications as Solid-Base Catalyst and Support for Pd Nanoparticles in Tandem Catalysis. Chem.-A Eur. J. 2017, 23, 4266-4270. [CrossRef] 
109. Niu, X.; Shi, Q.; Zhu, W.; Liu, D.; Tian, H.; Fu, S.; Cheng, N.; Li, S.; Smith, J.N.; Du, D.; et al. Unprecedented peroxidase-mimicking activity of single-atom nanozyme with atomically dispersed Fe-Nx moieties hosted by MOF derived porous carbon. Biosens. Bioelectron. 2019, 142, 111495. [CrossRef]

110. Lan, G.; Ye, Q.; Zhu, Y.; Tang, H.; Han, W.; Li, Y. Single-Site Au/Carbon Catalysts with Single-Atom and Au Nanoparticles for Acetylene Hydrochlorination. ACS Appl. Nano Mater. 2020, 3, 3004-3010. [CrossRef]

111. Kochubey, D.I.; Chesnokov, V.V.; Malykhin, S.E. Evidence for atomically dispersed Pd in catalysts supported on carbon nanofibers. Carbon N. Y. 2012, 50, 2782-2787. [CrossRef]

112. Chesnokov, V.V.; Kriventsov, V.V.; Malykhin, S.E.; Svintsitskiy, D.A.; Podyacheva, O.Y.; Lisitsyn, A.S.; Richards, R.M. Nature of active palladium sites on nitrogen doped carbon nanofibers in selective hydrogenation of acetylene. Diam. Relat. Mater. 2018, 89, 67-73. [CrossRef]

113. Feng, Q.; Zhao, S.; Xu, Q.; Chen, W.; Tian, S.; Wang, Y.; Yan, W.; Luo, J.; Wang, D.; Li, Y. Mesoporous Nitrogen-Doped Carbon-Nanosphere-Supported Isolated Single-Atom Pd Catalyst for Highly Efficient Semihydrogenation of Acetylene. Adv. Mater. 2019, 31, 1901024. [CrossRef]

114. Wu, K.; Zhan, F.; Tu, R.; Cheong, W.-C.; Cheng, Y.; Zheng, L.; Yan, W.; Zhang, Q.; Chen, Z.; Chen, C. Dopamine polymer derived isolated single-atom site metals/N-doped porous carbon for benzene oxidation. Chem. Commun. 2020, 56, 8916-8919. [CrossRef]

115. Liu, W.; Chen, Y.; Qi, H.; Zhang, L.; Yan, W.; Liu, X.; Yang, X.; Miao, S.; Wang, W.; Liu, C.; et al. A Durable Nickel Single-Atom Catalyst for Hydrogenation Reactions and Cellulose Valorization under Harsh Conditions. Angew. Chemie 2018, 130, 7189-7193. [CrossRef]

116. Liu, W.; Zhang, L.; Yan, W.; Liu, X.; Yang, X.; Miao, S.; Wang, W.; Wang, A.; Zhang, T. Single-atom dispersed Co-N-C catalyst: Structure identification and performance for hydrogenative coupling of nitroarenes. Chem. Sci. 2016, 7, 5758-5764. [CrossRef]

117. Long, X.; Li, Z.; Gao, G.; Sun, P.; Wang, J.; Zhang, B.; Zhong, J.; Jiang, Z.; Li, F. Graphitic phosphorus coordinated single Fe atoms for hydrogenative transformations. Nat. Commun. 2020, 11, 4074. [CrossRef]

118. Huang, R.; Cao, C.; Liu, J.; Zheng, L.; Zhang, Q.; Gu, L.; Jiang, L.; Song, W. Integration of Metal Single Atoms on Hierarchical Porous Nitrogen-Doped Carbon for Highly Efficient Hydrogenation of Large-Sized Molecules in the Pharmaceutical Industry. ACS Appl. Mater. Interfaces 2020, 12, 17651-17658. [CrossRef]

119. Zhang, L.; Wang, A.; Wang, W.; Huang, Y.; Liu, X.; Miao, S.; Liu, J.; Zhang, T. Co-N-C Catalyst for C-C Coupling Reactions: On the Catalytic Performance and Active Sites. ACS Catal. 2015, 5, 6563-6572. [CrossRef]

120. Liu, P.; Zheng, N. Coordination chemistry of atomically dispersed catalysts. Natl. Sci. Rev. 2018, 5, 636-638. [CrossRef]

121. Ma, D.W.; Li, T.; Wang, Q.; Yang, G.; He, C.; Ma, B.; Lu, Z. Graphyne as a promising substrate for the noble-metal single-atom catalysts. Carbon N. Y. 2015, 95, 756-765. [CrossRef]

Publisher's Note: MDPI stays neutral with regard to jurisdictional claims in published maps and institutional affiliations.

(C) 2020 by the authors. Licensee MDPI, Basel, Switzerland. This article is an open access article distributed under the terms and conditions of the Creative Commons Attribution (CC BY) license (http://creativecommons.org/licenses/by/4.0/). 